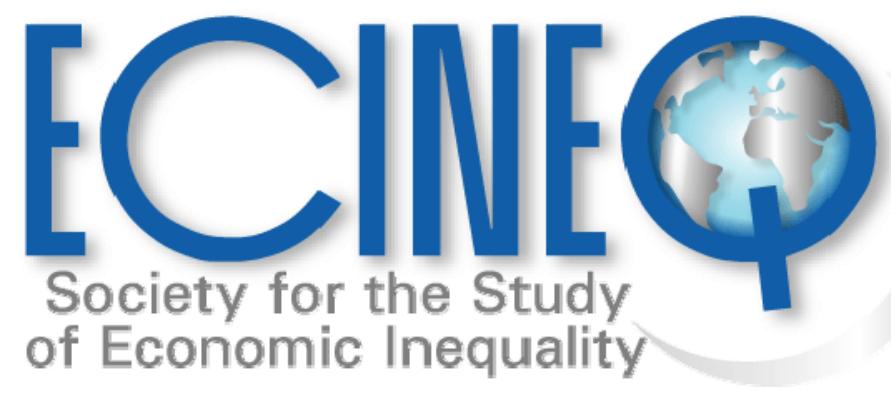

Working Paper Series

Occupational segregation of Hispanics in U.S. metropolitan areas

Olga Alonso-Villar

Carlos Gradin

Coral del Rio 


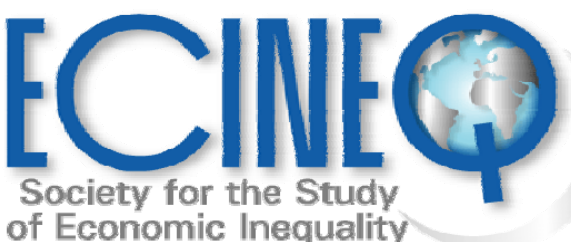

ECINEQ $2012-242$

January 2012

www.ecineq.org

\title{
Occupational segregation of Hispanics in U.S. metropolitan areas
}

\author{
Olga Alonso-Villar ${ }^{\dagger}$ \\ Carlos Gradin \\ Coral del Rio \\ Universidade de Vigo
}

\begin{abstract}
This paper quantifies the occupational segregation of Hispanics in the largest Hispanic enclaves of the U.S. Using a procedure based on propensity score, it also explores the role played by the characteristics of Hispanics in explaining the variation of segregation across metropolitan areas. The lowest conditional segregation generally appears in wellestablished immigrant gateways mainly located near the Mexican border. A regression analysis shows that segregation of Hispanic workers tends to be higher in relatively smaller and highlyeducated labor markets, with a lower proportion of Hispanics, and in areas where they face cooler feelings from the rest of the population.
\end{abstract}

Keywords: Occupational segregation; Hispanics; ethnicity; metropolitan areas; United States

JEL Classification: J15; J71; D63

\footnotetext{
* Financial support from the Ministerio de Ciencia e Innovación (grants ECO2011-23460 and ECO201021668-C03-03) and Xunta de Galicia (grant 10SEC300023PR) is gratefully acknowledged.

† Contact details: Universidade de Vigo; Facultade de CC. Económicas; Departamento de Economía Aplicada; Campus Lagoas-Marcosende s/n; 36310 Vigo; Spain. Tel.: +34 986812507; fax: +34 986812401; email: ovillar@uvigo.es.
} 


\section{Introduction}

In multiethnic and multiracial American society, many studies have documented that minorities have lower opportunities than whites. These inequalities result in spatial segregation (both across educational centers in school districts and neighborhoods in metropolitan areas), workplace and occupational segregation, and large wage gaps (Neal and Johnson, 1996; Reardon and Yun, 2001; Kim, 2002; Hirsch and Macpherson, 2004; Iceland, 2004; Bayer et al., 2004; Tomaskovic-Devey et al., 2006; Frankel and Volij, 2011). ${ }^{1}$ Most of this research has focused on the performance of African Americans, while the situation of other minorities has been less explored.

In the last years, the Hispanic population has started to receive more consideration in academia, given its outstanding and ever-increasing presence in the country. According to the 2010 Census, Hispanics represent $16.6 \%$ of the population residing in the U.S., growing from 35.3 million in 2000 to 50 million people in 2010, and contributing over half of the population growth of the country. With respect to Hispanics, the literature has provided evidence of wage disparities between this group and non-Hispanic whites (Bradbury, 2002; Black et al, 2006; Dávila and Mora, 2008; Stewart and Dixon, 2010). ${ }^{2}$ However, additional sources of inequality for Hispanics in the labor market, such as occupational and workplace segregation, have not received a great deal of attention until recently (exceptions are Alonso-Villar et al., 2012; Gabriel et al., 1999; Gradín, 2010; Hellerstein and Neumark, 2008; Queneau, 2009; and Tomaskovic et al., 2006).

This lack of literature may be a consequence of the tools usually employed to measure segregation, given that they allow quantifying either segregation between Hispanics and another group (mainly non-Hispanic whites, but also blacks or Asians) or overall multigroup segregation between whites, blacks, Hispanics, and Asians, for example. The former approach is based on pair-wise comparisons, a method that becomes cumbersome when many groups are involved, while the latter allows a general picture of segregation by race/ethnicity but not of the segregation of a particular group. A different approach is proposed in Alonso-Villar and Del Río (2010), where several

\footnotetext{
${ }^{1}$ For earlier works, see Theil and Finizza (1971), Farley (1977), and Massey and Denton (1987).

${ }^{2}$ Residential segregation for Hispanics has been documented as well (Frey and Farley, 1996; Logan et al., 2004; Reardon et al., 2009; Dickerson and Johnson, 2010; Lichter et al., 2010; Hao and Fong, 2011; Park and Iceland, 2011).
} 
measures are defined and axiomatically explored to quantify the segregation of any target group. These measures result from comparing the distribution of a target group across occupations with the distribution of total employment, and they are naturally related to overall segregation measures, given that the latter can be obtained as the weighted average of the segregation level of the groups into which the economy has been partitioned. Considering that the focus of this approach is the distribution of a target group across the whole set of jobs of the economy, rather than the disparities between the distribution of the group and that of another group, no pair-wise comparisons are required. ${ }^{3}$

Most studies on occupational segregation by ethnicity and race are undertaken at the national level, and there has been little inquiry into this issue at different regional scales (an exception is Gradín et al., 2011, who explore overall multigroup segregation at the state level). Thus, when analyzing geographical disparities in occupational segregation-mainly between blacks and whites-scholars have focused on regional variation between the South and the North. But the actual experience of segregation of a demographic group may depend on the characteristics of the local labor market in which the group works (Catanzarite, 2000; Cohen and Huffman, 2003), particularly with respect to the mix of jobs demanded and also the tolerance toward minorities. Research on occupational segregation at the local level is scarce, though, and, as far as we know, it has not focused on the performance of Hispanics.

This paper aims to shed some light on the different opportunities that Hispanics meet with across American cities. For that purpose, the occupational segregation level of Hispanics is quantified in metropolitan areas (MAs, henceforth) with a large presence of the group, showing the differences among them. In particular, comparisons between established immigrant gateways and new destinations are offered. Given that occupational segregation is a gender-sensitive phenomenon (Albelda, 1986; King, 1992; Reskin, 1999; Kauffman, 2010), the analysis is undertaken for women and men separately. To quantify the occupational segregation of Hispanics of each sex in each metropolitan area, the measures proposed by Alonso-Villar and Del Río (2010) are used.

\footnotetext{
${ }^{3}$ By using this approach, Alonso-Villar et al. (2012) quantify the segregation of several ethnic and racial groups in the U.S. at the national level.
} 
In comparing segregation across metropolitan areas, disparities can emerge as a result of geographical variation in the characteristics of Hispanic workers, such as attained education or immigration profiles. In this vein, Alonso-Villar et al. (2012) and Gradín (2010) show by different methodologies that those characteristics of Hispanics are, to a large extent, responsible for their segregation in the U.S. It is, therefore, convenient to compare segregation across metropolitan areas using a common distribution of the relevant characteristics of Hispanic workers. This allows us to separate differences in segregation across areas that result from geographical disparities in the distribution of Hispanic attributes (explained segregation) from those that could be entirely due to discrepancies in the characteristics of the areas (unexplained or conditional segregation).

As opposed to previous studies on occupational segregation at the metropolitan area level, this paper deals with segregation that is conditional on the distribution of characteristics of Hispanics across areas. In doing so, we borrow the methodology initially proposed by DiNardo et al. (1996) to analyze wage disparities, later adapted by Gradín (2010) to the analysis of overall segregation by race/ethnicity at the national level. The segregation of Hispanic women (or men) in each metropolitan area is obtained using an estimated counterfactual distribution in which the group is given the relevant characteristics it would have in a metropolitan area of reference. This is done by estimating their propensity score using a logit model. The difference between conditional and unconditional segregation in each metropolitan area provides a measure of the segregation that is actually explained by inequalities in workers' characteristics across areas. This explained term is additionally disaggregated into the detailed contribution of each covariate to identify which of these are more explicative. In order to obtain path-independent detailed contributions, we will use the Shapley decomposition (Shorrocks, 1999; Chantreuil and Trannoy, 1999). However, disparities among metropolitan areas may be not only the result of differences in the distribution of Hispanic characteristics, but also a consequence of characteristics of the areas. By using a regression analysis, this paper also explores to what extent spatial discrepancies on conditional segregation can be explained by metropolitan characteristics such as industrial composition, labor market conditions, characteristics of other demographic groups, and attitudes toward minorities. 
The paper is structured as follows. Section 2 first presents the segregation measures used in this study and later on offers the (unconditional) segregation levels of Hispanic women and men in metropolitan areas where this group has a large presence. In Section 3 , the conditional analysis is undertaken to explore to what extent differences in segregation are the result of specific characteristics of Hispanics across areas. Using a regression analysis, Section 4 investigates the role played by specific characteristics of metropolitan areas in explaining the remaining spatial disparities in segregation. Finally, Section 5 offers the main conclusions.

\section{Occupational Segregation of Hispanics in Selected MAs}

\subsection{Segregation Indices}

When exploring occupational (and residential) segregation by race/ethnicity in the U.S., most scholars consider pair-wise comparisons: Blacks-whites, Hispanics-non-Hispanic whites, Hispanics-blacks, black women-black men, black women-white women, and so on (King, 1992; Wang, 2008; Iceland and Nelson, 2008). Consequently, these studies actually measure black-white segregation, Hispanic-white segregation, Hispanic-black segregation, female-male black segregation, black-white female segregation and so on. When many groups are involved, these comparisons become cumbersome, and the performance of a target group is difficult to summarize. The measures proposed by Alonso-Villar and Del Río (2010) facilitate this analysis because the distribution of a target group across occupations is compared with the distribution of total employment. This means that Hispanic men are segregated, so long as they are overrepresented in some jobs and underrepresented in others (whether the latter are filled by non-Hispanic whites or by other minorities). These tools are introduced in what follows.

Let us denote by $c^{g} \equiv\left(c_{1}^{g}, c_{2}^{g}, \ldots, c_{J}^{g}\right)$ the distribution of the target group $g$ (Hispanic women or men in a given metropolitan area) among $J>1$ occupations, and by $t \equiv\left(t_{1}, t_{2}, \ldots, t_{J}\right)$ the employment structure of the economy in a metropolitan area (the corresponding subscript in dropped for simplicity). By comparing distribution $c^{g}$ with $t$, several indices can be defined, depending on how the differences among them are taken into account: 


$$
\begin{gathered}
G^{g}\left(c^{g} ; t\right)=\frac{\sum_{i, j} \frac{t_{i}}{T} \frac{t_{j}}{T}\left|\frac{c_{i}^{g}}{t_{i}}-\frac{c_{j}^{g}}{t_{j}}\right|}{2 \frac{C^{g}}{T}} \\
\Phi_{a}^{g}\left(c^{g} ; t\right)=\left\{\begin{array}{l}
\frac{1}{a(a-1)} \sum_{j} \frac{t_{j}}{T}\left[\left(\frac{c_{j}^{g} / C^{g}}{t_{j} / T}\right)^{a}-1\right] \text { if } a \neq 0,1 \\
\sum_{j} \frac{c_{j}^{g}}{C^{g}} \ln \left(\frac{c_{j}^{g} / C^{g}}{t_{j} / T}\right) \text { if } a=1 \\
D^{g}\left(c^{g} ; t\right)=\frac{1}{2} \sum_{j}\left|\frac{c_{j}^{g}}{C^{g}}-\frac{t_{j}}{T}\right|,
\end{array}\right.
\end{gathered}
$$

where $T=\sum_{j} t_{j}$ is the total number of workers in the metropolitan area and $C^{g}=\sum_{j} c_{j}^{g}$ is the total number of target workers in that location. The higher the value of these indices, the larger is the segregation of the target group. The first measure is a variation of the classic Gini index. The second represents a family of indices related to the generalized entropy family, where $a$ can be interpreted as a segregation sensitivity parameter, so that the lower its value, the higher the sensitivity of the index against employment movements involving occupations where the group has low representation $\left(\frac{x_{j}}{t_{j}}\right)$. The third measure is a variation of the index of dissimilarity. Both $G^{g}$ and $D^{g}$ take values within the interval $[0,1)$, while $\Phi_{a}^{g}$ is unbounded.

\subsection{Data}

The data used in this section come from the 2005-2007 Public Use Microdata Sample (PUMS) files of the American Community Survey (ACS). This survey was conducted by the U.S. Census Bureau throughout the U.S., using a series of monthly samples jointly accounting for $3 \%$ of the overall population living in housing units during the period (and 2\% of those living in group quarters during 2006 and 2007). We have chosen the 2005-2007 release rather than later releases of the ACS, to avoid the distortion produced by the soar in unemployment rates in 2008. In this way, we show the situation when the economy was still strong. As for occupations, we use the classification offered in the Current Population Survey, which is based on a detailed occupation recode of the Standard Occupational Classification System (SOC). The list 
includes 52 occupations. ${ }^{4}$ Considering that gender is a relevant variable in explaining occupational segregation and given that if no distinction is made between women and men, segregation may be underestimated, this paper treats each group separately. In this paper, MAs can be either metropolitan statistical areas or consolidated metropolitan statistical areas, as defined by the 2000 Census.

\subsection{Segregation of Hispanics across Selected MAs}

Table 1 shows several characteristics of the top 25 MAs with the highest proportions of Hispanic workers in the U.S. (i.e., these areas are the most important Hispanic enclaves in the country; for additional characteristics, see Table 6 in the Appendix).

The proportions of total Hispanic workers in these MAs range from 17.2\% in Los Angeles to $0.7 \%$ in Tucson. ${ }^{5}$ Altogether, the selected MAs account for $71.5 \%$ of all Hispanic workers. ${ }^{6}$ Regarding the representation of Hispanic workers with respect to the total number of workers in these areas, the values are between 5.8\% in Philadelphia and 89\% in McAllen. It is worth mentioning that in six MAs-McAllen, El Paso, San Antonio, Fresno, Miami, and Los Angeles-Hispanic workers are the majority group (columns 2-4). We also see that $37.9 \%$ of Hispanic workers in these areas were born in the U.S. (see last row), while $8.3 \%$ have lived in the country for 5 years or less. More than $50 \%$ of Hispanics in these places speak English fluently, while only $13.6 \%$ have a bachelor's degree (with remarkable differences across MAs).

\footnotetext{
${ }^{4}$ See Appendix B, Census Bureau (2007) for details. We discard the use of the SOC because classification at a 3-digit level (469 categories) would be problematic in most MAs, while classification at a 2-digit level (22 categories) is more aggregated than the one used here.

${ }^{5}$ Although the tables show the complete name, from this point on, for the sake of simplicity, these areas are simply labeled according to the first city of the corresponding area.

${ }^{6}$ Following the 2000 U.S. Census, these MAs account for $40.5 \%$ of total population, including both small MAs such as McAllen, El Paso, Albuquerque, Tucson, and Fresno (whose population is below a million) and the largest MAs in the U.S., such as New York and Los Angeles, with more than 15 million people (see Table 6 in the Appendix).
} 


\begin{tabular}{|c|c|c|c|c|c|c|c|c|c|}
\hline $\begin{array}{c}\text { MAs } \\
\text { (with State abbreviations) }\end{array}$ & $\begin{array}{c}\text { Proportion } \\
\text { of total } \\
\text { Hispanic } \\
\text { workers } \\
\frac{C^{H}}{\text { Total } C^{H}}\end{array}$ & $\begin{array}{c}\text { Share of } \\
\text { Hispanic } \\
\text { male } \\
\text { workers } \\
\frac{C^{H . M e n}}{T}\end{array}$ & $\begin{array}{c}\text { Share of } \\
\text { Hispanic } \\
\text { Female } \\
\text { workers } \\
\frac{C^{\text {H.Women }}}{T}\end{array}$ & 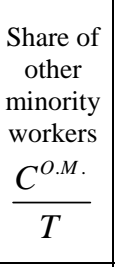 & $\begin{array}{c}\text { Hispanic } \\
\text { workers } \\
\text { born in } \\
\text { the U.S. } \\
(\%)\end{array}$ & $\begin{array}{c}\text { Hispanic } \\
\text { workers } \\
\text { with up } \\
\text { to } 5 \\
\text { years of } \\
\text { residence } \\
(\%)\end{array}$ & $\begin{array}{c}\text { Hispanic } \\
\text { workers } \\
\text { who } \\
\text { speak } \\
\text { only } \\
\text { English } \\
(\%)\end{array}$ & $\begin{array}{c}\text { Hispanic } \\
\text { workers } \\
\text { who } \\
\text { speak } \\
\text { English } \\
\text { very } \\
\text { well } \\
(\%) \\
\end{array}$ & $\begin{array}{l}\text { Hispanic } \\
\text { workers } \\
\text { with a } \\
\text { Bachelor's } \\
\text { degree } \\
(\%)\end{array}$ \\
\hline Albuquerque, NM & 0.8 & 22.4 & 18.4 & 10.1 & 79.1 & 3.9 & 47.9 & 34.8 & 15.3 \\
\hline Atlanta, GA & 1.2 & 6.2 & 2.5 & 33.4 & 15.7 & 24.0 & 11.7 & 25.1 & 14.6 \\
\hline Austin-San Marcos, TX & 1.2 & 17.4 & 10.5 & 12.1 & 57.5 & 8.6 & 25.5 & 39.8 & 15.6 \\
\hline Boston-Worcester-Lawrence, MA-NH-ME-CT & 1.0 & 3.5 & 2.8 & 11.3 & 26.9 & 9.2 & 14.1 & 41.5 & 18.1 \\
\hline Chicago-Gary-Kenosha, IL-IN-WI & 4.2 & 10.9 & 6.5 & 20.0 & 34.8 & 6.9 & 13.1 & 37.1 & 11.5 \\
\hline Dallas-Fort Worth, TX & 3.8 & 15.7 & 8.1 & 18.2 & 34.4 & 10.4 & 13.6 & 33.7 & 10.0 \\
\hline Denver-Boulder-Greeley, CO & 1.5 & 11.1 & 7.1 & 8.8 & 53.6 & 7.5 & 38.6 & 22.8 & 12.0 \\
\hline El Paso, TX & 1.1 & 42.6 & 35.8 & 4.5 & 59.8 & 3.2 & 9.3 & 59.9 & 15.6 \\
\hline Fresno, CA & 1.0 & 26.7 & 17.9 & 13.3 & 53.5 & 5.6 & 29.7 & 34.0 & 8.1 \\
\hline Houston-Galveston-Brazoria, TX & 4.1 & 19.5 & 10.9 & 21.9 & 38.4 & 7.5 & 14.0 & 36.5 & 9.8 \\
\hline Las Vegas, NV-AZ & 1.2 & 15.0 & 9.0 & 17.4 & 33.5 & 11.7 & 19.3 & 29.9 & 7.3 \\
\hline Los Angeles-Riverside-Orange County, CA & 17.2 & 24.3 & 16.4 & 20.2 & 37.6 & 6.0 & 17.3 & 36.1 & 9.6 \\
\hline McAllen-Edinburg-Mission, TX & 1.1 & 48.1 & 40.9 & 2.2 & 61.2 & 5.2 & 6.3 & 58.9 & 14.3 \\
\hline Miami-Fort Lauderdale, FL & 4.8 & 25.2 & 20.4 & 21.7 & 19.8 & 10.4 & 5.4 & 46.9 & 26.0 \\
\hline New York, Northern New Jersey, Long Island, NY-NJ-CT-PA & 10.2 & 10.4 & 8.1 & 24.4 & 30.1 & 9.0 & 12.9 & 41.1 & 17.3 \\
\hline Orlando, FL & 1.1 & 12.0 & 8.5 & 18.3 & 30.5 & 13.3 & 13.2 & 46.5 & 18.1 \\
\hline Philadelphia-Wilmington-Atlantic City, PA-NJ-DE-MD & 0.9 & 3.3 & 2.5 & 21.2 & 36.7 & 13.9 & 18.6 & 36.8 & 13.0 \\
\hline Phoenix-Mesa, AZ & 2.7 & 17.1 & 9.8 & 9.0 & 42.7 & 12.3 & 23.7 & 30.2 & 8.6 \\
\hline Sacramento-Yolo, CA & 0.8 & 9.8 & 6.7 & 20.1 & 50.7 & 8.1 & 35.6 & 27.4 & 15.4 \\
\hline San Antonio, TX & 2.2 & 27.5 & 22.9 & 9.2 & 76.3 & 3.0 & 27.7 & 50.2 & 13.9 \\
\hline San Diego, CA & 2.0 & 15.6 & 11.0 & 17.8 & 43.0 & 5.0 & 20.9 & 39.6 & 12.8 \\
\hline San Francisco-Oakland-San Jose, CA & 4.0 & 12.7 & 8.0 & 29.4 & 38.9 & 8.2 & 23.3 & 32.3 & 14.2 \\
\hline Tampa-St. Petersburg-Clearwater, FL & 0.9 & 8.1 & 5.9 & 14.3 & 37.4 & 10.5 & 19.9 & 43.7 & 18.4 \\
\hline Tucson, AZ & 0.7 & 17.3 & 13.3 & 8.9 & 62.0 & 6.5 & 27.5 & 45.5 & 12.6 \\
\hline Washington-Baltimore, DC-MD-VA-WV & 1.9 & 4.8 & 3.3 & 31.1 & 19.7 & 15.0 & 14.3 & 33.8 & 21.6 \\
\hline Total & 71.5 & 13.6 & 9.2 & 20.9 & 37.9 & 8.3 & 17.2 & 38.0 & 13.6 \\
\hline
\end{tabular}

Table 1. Characteristics of selected metropolitan areas

The (unconditional) segregation of Hispanic women and men is shown in Table 2, where three indices are shown: $\Phi_{1}^{H}, D^{H}$ and $G^{H}$. The ranking of the areas according to these indices is rather similar. Thus, the Spearman rank correlation between the first index and the others ranges between 0.98 and 0.99 for men, and between 0.95 and 0.99 for women. From this point on, we will focus on the results according to index $\Phi_{1}^{H}$, which demonstrates intermediate sensitivity toward what happens in occupations where Hispanics have a low representation. 


\begin{tabular}{|c|c|c|c|c|c|c|c|}
\hline MAs & $\Phi_{1}^{\text {Hispanics }}$ & $\Phi_{1}^{H . M e n}$ & $\Phi_{1}^{\text {H.Women }}$ & $D^{H . M e n}$ & $D^{\text {H.Women }}$ & $G^{\text {H.Men }}$ & $G^{\text {H.Women }}$ \\
\hline Albuquerque, NM & 0.059 & 0.249 & 0.243 & 0.296 & 0.273 & 0.388 & 0.370 \\
\hline Atlanta, GA & 0.486 & 0.796 & 0.315 & 0.507 & 0.303 & 0.632 & 0.426 \\
\hline Austin-San Marcos, TX & 0.173 & 0.404 & 0.278 & 0.384 & 0.304 & 0.475 & 0.403 \\
\hline $\begin{array}{l}\text { Boston-Worcester-Lawrence, MA-NH- } \\
\text { ME-CT }\end{array}$ & 0.218 & 0.398 & 0.276 & 0.386 & 0.275 & 0.478 & 0.398 \\
\hline Chicago-Gary-Kenosha, IL-IN-WI & 0.228 & 0.405 & 0.230 & 0.407 & 0.272 & 0.487 & 0.368 \\
\hline Dallas-Fort Worth, TX & 0.262 & 0.482 & 0.283 & 0.432 & 0.302 & 0.523 & 0.411 \\
\hline Denver-Boulder-Greeley, CO & 0.249 & 0.501 & 0.279 & 0.439 & 0.298 & 0.529 & 0.407 \\
\hline El Paso, TX & 0.017 & 0.128 & 0.214 & 0.218 & 0.245 & 0.284 & 0.325 \\
\hline Fresno, CA & 0.095 & 0.292 & 0.203 & 0.348 & 0.234 & 0.419 & 0.325 \\
\hline Houston-Galveston-Brazoria, TX & 0.187 & 0.404 & 0.324 & 0.400 & 0.322 & 0.484 & 0.439 \\
\hline Las Vegas, NV-AZ & 0.223 & 0.421 & 0.337 & 0.398 & 0.317 & 0.496 & 0.440 \\
\hline $\begin{array}{l}\text { Los Angeles-Riverside-Orange County, } \\
\text { CA }\end{array}$ & 0.128 & 0.294 & 0.232 & 0.345 & 0.281 & 0.420 & 0.366 \\
\hline McAllen-Edinburg-Mission, TX & 0.005 & 0.155 & 0.225 & 0.238 & 0.265 & 0.311 & 0.346 \\
\hline Miami-Fort Lauderdale, FL & 0.021 & 0.163 & 0.174 & 0.228 & 0.230 & 0.317 & 0.304 \\
\hline $\begin{array}{l}\text { New York, Northern New Jersey, Long } \\
\text { Island, NY-NJ-CT-PA }\end{array}$ & 0.160 & 0.347 & 0.238 & 0.373 & 0.283 & 0.449 & 0.379 \\
\hline Orlando, FL & 0.099 & 0.312 & 0.213 & 0.341 & 0.252 & 0.429 & 0.340 \\
\hline $\begin{array}{l}\text { Philadelphia-Wilmington-Atlantic City, } \\
\text { PA-NJ-DE-MD }\end{array}$ & 0.275 & 0.540 & 0.260 & 0.442 & 0.288 & 0.536 & 0.394 \\
\hline Phoenix-Mesa, AZ & 0.212 & 0.464 & 0.247 & 0.427 & 0.284 & 0.517 & 0.382 \\
\hline Sacramento-Yolo, CA & 0.195 & 0.452 & 0.228 & 0.408 & 0.247 & 0.497 & 0.361 \\
\hline San Antonio, TX & 0.049 & 0.199 & 0.219 & 0.274 & 0.251 & 0.348 & 0.345 \\
\hline San Diego, CA & 0.151 & 0.312 & 0.274 & 0.346 & 0.298 & 0.430 & 0.397 \\
\hline San Francisco-Oakland-San Jose, CA & 0.250 & 0.479 & 0.280 & 0.430 & 0.309 & 0.521 & 0.409 \\
\hline Tampa-St. Petersburg-Clearwater, FL & 0.113 & 0.320 & 0.182 & 0.333 & 0.248 & 0.423 & 0.328 \\
\hline Tucson, AZ & 0.109 & 0.341 & 0.262 & 0.369 & 0.299 & 0.449 & 0.382 \\
\hline Washington-Baltimore, DC-MD-VA-WV & 0.365 & 0.621 & 0.418 & 0.453 & 0.329 & 0.557 & 0.462 \\
\hline Unweighted average & 0.173 & 0.379 & 0.257 & 0.369 & 0.280 & 0.456 & 0.380 \\
\hline
\end{tabular}

Table 2. Unconditional segregation of Hispanic workers in selected MAs: $\Phi_{1}^{H}, D^{H}$ and $G^{H}$.

Overall, Table 2 shows that unconditional segregation tends to be lower in those places where Hispanics, especially men, are more highly represented with respect to total number of workers in the area. ${ }^{7}$ In fact, the Spearman rank correlation between representation of the group in the local market and segregation is negative for both men and women (-0.74 and -0.42 , respectively). Moreover, MAs where Hispanic workers represent more than $40 \%$ of total workers show the lowest Hispanic male segregation levels. The relationship between

\footnotetext{
${ }^{7}$ It is worth mentioning that the indices used in this paper are scale invariant and, therefore, they do not depend on the total numbers of the target group, but rather on the group's distribution across occupations. In any case, those places where most workers are Hispanics are expected to fill most jobs with this group which, ceteris paribus, leads to lower segregation.
} 
segregation and Hispanic representation is not one-to-one, though. Thus, for example, Philadelphia has a similar segregation level for Hispanic men as Denver, in spite of these men having very different representation (3.3\% of workers versus $11.1 \%$; see Table 1$)$. In the case of women, MAs such as Tampa, Orlando, Sacramento, and Chicago show low segregation, though female Hispanic representation in those areas is below 8.5\% (Hispanic representation of both sexes in these areas is below 20.5\%).

Table 2 also shows that a portion of the occupational segregation of Hispanic women and men is related to gender segregation. In fact, when computing occupational segregation for Hispanic workers jointly considered, in most cases, the index decreases with respect to that of Hispanic women or men (columns 1-3). Moreover, in some MAs where Hispanic workers are the majority group, their segregation levels are almost explained by disparities between the two sexes (see McAllen, El Paso, and San Antonio). Thus, despite both groups sharing a high presence in two occupations“janitors/building/maid/housekeeping cleaners, pest control and grounds maintenance workers" and "production occupations"-women mainly work as "cashiers, counter and rental clerks and sales workers," and in "office and administration support occupations," while men are largely occupied as "ambulance drivers and attendants, bus/taxi drivers, and other transportation and material moving occupations," "carpet, floor and tile installers and finishers, construction laborers, and the like," and “installation, maintenance, and repair workers,” which are extremely masculinized occupations.

Table 2 also reveals that segregation in most areas is higher for men than for women, which corroborates previous work by Alonso-Villar et al. (2012), who reached the same conclusion considering a broader classification of occupations (their list included 22 occupations). Exceptions are El Paso, McAllen, Miami, and San Antonio, which show higher segregation for women. These are areas having in common a low level of segregation for Hispanics together with a high level of representation of this group. This suggests that the segregation of women tends to be higher than that of men in areas where gender explains most of the segregation of Hispanics.

The general pattern of segregation being higher for men does not seem to be a consequence of a higher concentration of Hispanic men in a fewer range of occupations. In fact, if we choose those occupations adding up $10 \%$ of total employment and having the lowest representation of Hispanic women, we find that only $0.9 \%$ of Hispanic 
women work there. The corresponding figure in the case of Hispanic men is $1.9 \%$. If we consider instead those occupations with the lowest presence of these groups and accounting for $20 \%$ of total employment, we find that only $3 \%$ of Hispanic women work in such occupations, while the corresponding percentage for their male counterparts is almost 5\%. How, then, can we explain the higher segregation for men? The explanation does not seem to rest on gender disparities in occupations where Hispanic women and men have low levels of representation, but in those where they tend to concentrate. In fact, there is no occupation where Hispanic women represent more than $25 \%$ of total employment, while there are several occupations for which Hispanic men make up around $50 \%$ of workers. In line with these figures, the isolation index of Hispanic men is higher than that of Hispanic women for all selected MAs (the average isolation index for Hispanic women is 0.07 and for men 0.16$){ }^{8}$ This suggests that Hispanic men are more concentrated in occupations with a lower presence of other groups. Consequently, the distribution of Hispanic men across occupations departs from that of total employment to a higher extent than that of Hispanic women. The fact that Hispanic male workers have a lower human capital may explain these gender disparities (38\% of Hispanic male workers in our selected MAs have less than high school, and $32 \%$ do not speak English or do not speak well, while the corresponding figures for Hispanic female workers are $26 \%$ and $23 \%$, respectively). ${ }^{9}$

Spatial disparities in male segregation are also higher than in female segregation (the coefficients of variation are 0.40 and 0.21 , respectively). This difference by gender is not due to disparities among MAs with low segregation (male segregation in El Paso is 0.13, and female segregation in Miami is 0.17 ) but among MAs in the top tail of the corresponding distribution, given that the values for men in MAs with the highest male segregation almost double those of women in MAs with the highest female segregation (male values are 0.80 in Atlanta, 0.60 in Washington D.C., and 0.54 in Philadelphia, while female values are 0.42 in Washington D.C., 0.34 in Las Vegas, and 0.32 in Houston).

\footnotetext{
8 The isolation index is a very popular tool in the sociology field. In our case, it measures the degree of exposure, within occupations, of Hispanic women (or men) towards individuals of the same group. For a formal definition of this index, see Cutler et al. (2008).

9 This human capital discrepancy can be a consequence of gender disparities in labor force participation rates (the rate for Hispanic women is $62 \%$ and for men $81 \%$ ). Disparities for other groups are less acute (the labor force participation rate for non-Hispanic women is $70 \%$ while that of their male counterparts is $79 \%)$.
} 
Exploring the performance of each MA in more detail, we find that those places where women are more segregated tend to be the most segregated places for men as well (even thought the segregation levels are rather different between the two sexes). This is the case of Washington D.C., Atlanta, Dallas, San Francisco, and Denver. Relevant exceptions are Las Vegas and Houston-which are among those places where women experienced their highest segregation but which do not have equally high positions for the male rankings — and Philadelphia, Phoenix, and Sacramento, where the opposite holds. The MAs with the lowest segregation levels for both women and men include Miami and El Paso, although there are other places where both sexes also have low segregation levels (McAllen, San Antonio, and Fresno).

Regarding the biggest MAs, we also find disparities between the sexes. Thus, in the case of women, Chicago, New York, and Los Angeles exhibit segregation levels below the average and similar to one another. By contrast, in the male case, there are remarkable differences among these areas: Chicago has a segregation level above the average, New York is slightly below the average, and Los Angeles shows a low level of segregation.

Finally, we do not find a clear geographic pattern of segregation, except the low segregation exhibited in MAs near to the Mexican border, where the representation of Hispanics is extraordinarily high. In fact, for both women and men, we see remarkable disparities among areas both on the East and West Coasts.

\section{Spatial Disparities in Segregation: Controlling for Characteristics of Hispanics across MAs}

\subsection{Theoretical Perspectives on Segregation}

Differences in occupational segregation among metropolitan areas may arise from several sources, including characteristics of Hispanics and characteristics of the areas. On the one hand, spatial disparities could be the result of differences in education and English fluency — which strongly depends on the years of residence in the country-as human capital is one of the factors explaining race-sex segregation in the labor market 
(for recent works, see Hellerstein and Neumark, 2008; Maxwell, 2010; Kaufman, 2010; Gradín, 2010; Alonso-Villar et al., 2012). Another source of variability may derive from the internal diversity of the group with regard to age, race (white/non-white), and country of origin, given that these groups may be unequally perceived by employers. ${ }^{10}$

Geographical disparities in the occupational segregation level of Hispanics across the U.S. may also emerge as a result of discrepancies in the characteristics of the areas. Thus, areas may differ in attitude toward some demographic groups (black women historically have been more segregated in the South; King, 1992). In addition, the industrial composition of local labor markets can affect segregation, as pointed out in the sociological literature. In this regard, large labor markets with a strong public sector or a high representation of manufacturing are expected to have lower occupational segregation, as these sectors "are more likely to operate according to universalistic criteria” (Semyonov et al., 2000, p. 177). Moreover, according to segmentation and queue theories, which maintain that jobs are allocated among workers in a stratified way so that the advantaged group fills the best jobs (Reskin, 1999; Kaufman, 2002), the performance of a minority in a local labor market is likely to depend on the representation of other disadvantaged minorities (Semyonov et al., 2000; Ovadia, 2003), although the final result does depend on how the market ranks these minorities.

In what follows, we control for differences in the main characteristics of Hispanics (age, immigration profile, English proficiency, education, origin, and race) across selected MAs analyzed in the previous section. For that purpose, we adapt the propensity score method proposed DiNardo et al. (1996) to our context. In a second stage (see Section 4), we will use a larger sample of MAs in order to ascertain which characteristics of the areas explain to a greater extent the conditional segregation of Hispanics at the metropolitan are level.

\subsection{Method Based on Propensity Score}

We first classify Hispanic women and men into mutually exclusive subgroups or "cells" according to their main characteristics: age, race, origin, educational attainment, English fluency, and immigration profile. One of these subgroups would be that of white

\footnotetext{
${ }^{10}$ As defined in the ACS, country of origin can be understood as heritage, country of birth, or country of ancestors.
} 
Mexican women aged above 45 years who have lived more than 15 years in the U.S., have a university degree, and speak English fluently. If $M A$ is the categorical variable representing metropolitan area and $z \equiv\left(z_{1}, \ldots, z_{k}\right)$ is the vector of $k$ covariates describing the attributes of each cell, the discrete density function of employment across occupations in metropolitan area $l$ can be written as:

$$
f_{l}(o)=f(o \mid M A=l)=\int_{z} f(o \mid z, M A=l) f(z \mid M A=l) d z,
$$

where $f(o \mid z, M A=l)$ is the density function corresponding to the distribution across occupations of workers in $l$ having attributes $z$, and $f(z \mid M A=l)$ is the attribute density in location $l$. To construct the counterfactual distribution of the above density function, $\tilde{f}_{l}(o)$, we assume that the distribution of employment in each cell across occupations does not depend on the distribution of attributes (i.e., if $f(o \mid z, M A=l)$ and $f(z \mid M A=l)$ are independent). Then, we keep the observed distribution of employment in each cell across occupations unaltered (i.e., $f(o \mid z, M A=l)$ ), while replacing the density function of the distribution of characteristics in metropolitan area $l$ with that of an area of reference (in our case, this area is Los Angeles [LA]). Therefore, the counterfactual distribution for location $l$

$$
\tilde{f}_{l}(o)=\int_{z} f(o \mid z, M A=l) f(z \mid M A=L A) d z
$$

represents the occupational distribution that would prevail in metropolitan area $l$ if each subgroup of individuals (defined by the cross of the main characteristics defined above) kept its own conditional probability of being in a given occupation, but Hispanic women (or men) in $l$ had the same characteristics as in LA in terms of immigration profile, educational level, etc.

One could proxy $f(z \mid M A=L A)$ by the frequency distribution of attributes empirically observed in LA, provided that all covariates in $z$ are dummies (as in our analysis). However, this process is cumbersome when many categories are involved, and it could be problematic if some cells are empty. Furthermore, it would be difficult to separate the individual effects of each covariate on segregation. To overcome these problems, we follow DiNardo et al. (1996) and re-formulate the counterfactual density in such a way 
that it can be simply obtained from reweighting the original observations in location $l$ by $\Psi_{z}=\frac{f(z \mid M A=L A)}{f(z \mid M A=l)}$ :

$$
\tilde{f}_{l}(o)=\int_{z} f(o \mid z, M A=l) \Psi_{z} f(z \mid M A=l) d z=\int_{z} \Psi_{z} f(o, z \mid M A=l) d z
$$

By using Bayes' theorem, weights can be rewritten as the product of two ratios that can be easily estimated from the data:

$$
\Psi_{Z}=\frac{\frac{\operatorname{Pr}(M A=L A \mid \mathrm{z})}{\operatorname{Pr}(\mathrm{MA}=L A)}}{\frac{\operatorname{Pr}(M A=l \mid \mathrm{z})}{\operatorname{Pr}(\mathrm{MA}=l)}}=\frac{\operatorname{Pr}(\mathrm{MA}=l)}{\operatorname{Pr}(\mathrm{MA}=L A)} \frac{\operatorname{Pr}(M A=L A \mid \mathrm{z})}{\operatorname{Pr}(M A=l \mid \mathrm{z})},
$$

where the first component is approximated by the ratio between the population samples in both MAs and the second component is obtained by estimating the probability of an individual with attributes $z$ to belong to LA rather than to $l$ using a binary probability model. We estimate the following logit model,

$$
\operatorname{Pr}(M A=L A \mid z)=\frac{\exp (z \hat{\beta})}{1+\exp (z \hat{\beta})},
$$

over the pool sample with observations from both MAs, where $\hat{\beta}$ is the associated vector of estimated coefficients.

Thus, this method allows us to construct a counterfactual distribution for female (male) Hispanic workers in each metropolitan area where the original observations are reweighted, taking into account their probability of belonging to the area of reference based on its own characteristics. The segregation level obtained in the corresponding counterfactual distribution reflects the amount of unexplained segregation in location $l$ that remains after controlling for differences of the characteristics of the group across MAs. After completing the same exercise for every MA, we can compare segregation across locations in the U.S. under a similar distribution of characteristics. Consequently, spatial variability will only reflect geographical disparities in the conditional distributions of Hispanic women (or men) across occupations. 
As mentioned, the difference between unconditional and conditional segregation provides a measure of the segregation that is actually explained by our covariates $z{ }^{11}$ This explained term can be additionally disaggregated into the detailed contribution of each factor to identify which among them are the more explicative (see Gradín, 2010). These contributions are obtained by using the Shapley decomposition (Shorrocks, 1999; Chantreuil and Trannoy, 1999; Sastre and Trannoy, 2002). ${ }^{12}$ The main advantage of this decomposition, widely used in income distribution analyses, is that the contributions of covariates are path independent and sum up the overall explained segregation.

\subsection{Conditional Segregation of Hispanics in Selected MAs}

To control for the attributes of Hispanics, we now compute the conditional segregation of Hispanic women and men. This means that the segregation of Hispanic women (men) in all areas is compared based on a common distribution of worker's characteristics: Those within the reference area in terms of age, country of origin, race, immigration profile, English fluency, and education. ${ }^{13}$ In doing so, Hispanic women (men) are partitioned into several subgroups according to the above covariates. Using the propensity score method, each subgroup in the area is given the weight it has in the area of reference, while keeping its original distribution across occupations unaltered. In this study, we choose Los Angeles as the area of reference because: a) it is the area where Hispanics have the largest presence (17.2\% of all Hispanic workers in the U.S. are in

\footnotetext{
${ }^{11}$ This is in line with the conventional wage gap decomposition in the explained and unexplained effects (characteristics and coefficients, respectively).

${ }^{12}$ To obtain the contribution of education, for example, we use the logit coefficients as follows: First, we calculate the prediction of $\operatorname{Pr}(M A=L A \mid z)$ by assuming that all coefficients except those of education dummies are zero, and then we compare the conditional segregation resulting from this new counterfactual to the unconditional segregation of the MA. Next, we calculate the prediction of the aforementioned probability, assuming that the coefficients of all covariates, except education and another covariate (e.g., immigration profile), are zero. The resulting counterfactuals are then compared to obtain the marginal contribution of education when immigration has been taken into account. Similarly, the analysis should be repeated when origin, rather than immigration, is the first factor to change. Following the same procedure, we have to consider all possible sequences where education is the third rather than the second factor to change. Averaging over all possible marginal contributions of education, we compute the contribution of this covariate to explained segregation.

${ }^{13}$ Individuals are ranged into three age groups: less than 30 years old, between 30 and 45, and above 45. Five groups of country of origin (Mexican, Puerto Rican, Cuban, Central Americans, and Rest of Hispanics) and two races (whites and non-whites) are considered. Regarding attained education, the levels are: less than high school, high school diploma, some college or associate degree, and bachelor's degree or higher. The immigration profile distinguishes among those born in the U.S., immigrant with up to 5 years of residence, between 6 and 10 years of residence, between 11 and 15, and more than 15 . With respect to English proficiency, five classes are grouped: speaking only English, speaking English very well, well, not well, and not at all.
} 
this area, as shown in Table 1); and b) it has a large representation of Mexicans, which is a group with a high representation in most MAs of the country. ${ }^{14}$ Conditional segregation is then the segregation obtained when using this counterfactual distribution. As an example of the procedure used to compute conditional segregation, Table 8 in the Appendix shows the auxiliary logit regressions used for estimating the re-weighting factors in New York (the probability of being from Los Angeles was estimated in the pooled sample of Hispanics workers in Los Angeles and New York). Tables 3 and 4 report the conditional and unconditional segregation levels of selected metropolitan areas for Hispanic men and women, respectively, according to index $\Phi_{1}^{H}$, together with the factors explaining the corresponding changes. ${ }^{15}$

The average conditional segregation of both female and male Hispanics increases compared to the average unconditional segregation because, in general, the characteristics of Hispanic workers in Los Angeles tend to be more "segregative" than those in other areas. On the other hand, as expected, the coefficient of variation decreases, especially for men (25\% versus $19 \%$ for women). This reduction can be interpreted as the percentage of disparities in the segregation level of Hispanics across selected areas that is explained by the inequality in the geographical distribution of Hispanic worker characteristics. Table 7 in the Appendix reveals that the conditional segregation rankings vary with respect to the unconditional rankings, increasing the (negative) correlation between segregation and the proportion of Hispanic workers in the area, especially in the case of males (the Spearman rank correlation for men changes from -0.74 to -0.85 and for women from -0.42 to -0.46$)$. Therefore, the higher the representation of male (female) Hispanic workers in an area, the lower is the segregation of Hispanic men (women).

\footnotetext{
${ }^{14}$ If, for example, New York, where 27\% of Hispanics are Puerto Ricans, was used, we would have to strongly increase the weight of this group in many MAs with low numbers of Puerto Ricans in the sample. This would lead to wrong estimates. The same problem exists if choosing other areas with a high representation of Hispanics from countries other than Mexico.

${ }^{15}$ In the case of conditional segregation, we also compute the estimates for index $G^{H}$ and $D^{H}$. The Spearman rank correlations between $\Phi_{1}^{H}$ and the other two are 0.94 and 0.98 for men, and 0.85 and 0.96 for women, respectively. Therefore, the rankings according to the three indices are rather similar.
} 


\begin{tabular}{|c|c|c|c|c|c|c|c|c|c|c|c|c|c|c|c|c|}
\hline \multirow[b]{2}{*}{ MAs } & \multicolumn{2}{|c|}{ Male Segregation } & \multicolumn{7}{|c|}{ Change in segregation } & \multicolumn{7}{|c|}{ Change as percentage of unconditional segregation } \\
\hline & Uncond. & Cond. & All & Age & Immig. & English & Education & Country & Race & All & Age & Immig. & English & Education & Country & Race \\
\hline Albuquerque & 0.249 & 0.436 & 0.187 & 0.001 & 0.116 & 0.016 & -0.026 & 0.078 & 0.001 & 74.9 & 0.6 & 46.5 & 6.6 & -10.4 & 31.4 & 0.3 \\
\hline Atlanta & 0.796 & 0.729 & -0.067 & 0.004 & -0.288 & 0.056 & 0.019 & 0.143 & 0.000 & -8.4 & 0.5 & -36.2 & 7.1 & 2.3 & 17.9 & 0.0 \\
\hline Austin-SM & 0.404 & 0.479 & 0.075 & -0.001 & 0.048 & 0.010 & -0.005 & 0.026 & -0.003 & 18.4 & -0.2 & 12.0 & 2.4 & -1.3 & 6.3 & -0.8 \\
\hline Boston-W-L & 0.398 & 0.514 & 0.116 & 0.007 & -0.081 & 0.027 & 0.022 & 0.137 & 0.005 & 29.1 & 1.7 & -20.4 & 6.7 & 5.5 & 34.3 & 1.4 \\
\hline Chicago-G-K & 0.405 & 0.392 & -0.014 & 0.000 & -0.033 & -0.019 & 0.029 & 0.015 & -0.006 & -3.3 & 0.1 & -8.0 & -4.8 & 7.2 & 3.8 & -1.6 \\
\hline Dallas-FW & 0.482 & 0.411 & -0.071 & -0.001 & -0.034 & 0.001 & -0.033 & 0.004 & -0.007 & -14.7 & -0.2 & -6.9 & 0.1 & -6.9 & 0.8 & -1.5 \\
\hline Denver-B-G & 0.501 & 0.570 & 0.069 & -0.002 & 0.011 & 0.079 & -0.048 & 0.037 & -0.008 & 13.7 & -0.3 & 2.2 & 15.7 & -9.7 & 7.4 & -1.6 \\
\hline El Paso & 0.128 & 0.209 & 0.081 & -0.005 & 0.043 & 0.000 & 0.026 & 0.007 & 0.010 & 63.2 & -3.9 & 33.3 & 0.1 & 20.5 & 5.3 & 7.8 \\
\hline Fresno & 0.292 & 0.293 & 0.001 & 0.000 & 0.032 & 0.002 & -0.026 & -0.002 & -0.005 & 0.2 & 0.0 & 11.1 & 0.7 & -9.0 & -0.7 & -1.8 \\
\hline Houston-G-B & 0.404 & 0.397 & -0.007 & -0.001 & 0.013 & -0.008 & -0.030 & 0.008 & 0.010 & -1.8 & -0.3 & 3.3 & -1.9 & -7.4 & 2.0 & 2.6 \\
\hline Las Vegas & 0.421 & 0.370 & -0.051 & 0.002 & -0.069 & 0.045 & -0.037 & 0.017 & -0.010 & -12.2 & 0.5 & -16.4 & 10.6 & -8.8 & 4.1 & -2.3 \\
\hline L. Angeles-R-OC & 0.294 & 0.294 & & & & & & & & & & & & & & \\
\hline McAllen-E-M & 0.155 & 0.164 & 0.009 & -0.006 & 0.035 & -0.025 & 0.013 & -0.008 & 0.001 & 5.8 & -4.2 & 22.5 & -16.3 & 8.3 & -5.3 & 0.8 \\
\hline Miami-FL & 0.163 & 0.341 & 0.178 & 0.001 & -0.051 & -0.019 & 0.047 & 0.189 & 0.012 & 108.8 & 0.3 & -31.2 & -11.8 & 28.5 & 115.5 & 7.5 \\
\hline New Y.-NNJ- LI & 0.347 & 0.460 & 0.113 & 0.000 & -0.122 & -0.025 & 0.026 & 0.237 & -0.003 & 32.6 & -0.1 & -35.2 & -7.1 & 7.6 & 68.2 & -0.9 \\
\hline Orlando & 0.312 & 0.515 & 0.202 & -0.001 & -0.143 & -0.012 & 0.012 & 0.337 & 0.008 & 64.7 & -0.3 & -45.6 & -3.7 & 3.9 & 107.9 & 2.5 \\
\hline Philadelphia-W-AC & 0.540 & 0.609 & 0.069 & -0.001 & -0.197 & -0.038 & -0.030 & 0.334 & 0.001 & 12.7 & -0.2 & -36.5 & -7.1 & -5.5 & 61.8 & 0.2 \\
\hline Phoenix-M & 0.464 & 0.420 & -0.044 & -0.002 & -0.045 & 0.023 & -0.015 & -0.002 & -0.004 & -9.6 & -0.4 & -9.6 & 5.0 & -3.2 & -0.4 & -1.0 \\
\hline Sacramento-Y & 0.452 & 0.538 & 0.086 & -0.002 & \begin{tabular}{|l|}
-0.024 \\
\end{tabular} & 0.036 & 0.066 & 0.014 & -0.005 & 19.0 & -0.4 & -5.3 & 8.1 & 14.7 & 3.0 & -1.1 \\
\hline San Antonio & 0.199 & 0.322 & 0.123 & -0.001 & 0.098 & -0.004 & 0.008 & 0.013 & 0.009 & 61.8 & -0.8 & 49.4 & -2.1 & 3.9 & 6.8 & 4.5 \\
\hline San Diego & 0.312 & 0.380 & 0.067 & 0.000 & -0.004 & 0.027 & 0.041 & 0.000 & 0.002 & 21.5 & 0.1 & -1.3 & 8.8 & 13.2 & 0.1 & 0.6 \\
\hline S. Francisco-O-SJ & 0.479 & 0.521 & 0.043 & 0.000 & -0.047 & 0.036 & 0.043 & 0.011 & 0.000 & 8.9 & -0.1 & -9.8 & 7.5 & 9.0 & 2.4 & -0.1 \\
\hline Tampa-SP-C & 0.320 & 0.592 & 0.272 & 0.000 & \begin{tabular}{|l|}
-0.127 \\
\end{tabular} & 0.045 & -0.008 & 0.359 & 0.003 & 85.0 & 0.1 & -39.7 & 14.0 & -2.4 & 112.0 & 1.1 \\
\hline Tucson & 0.341 & 0.449 & 0.107 & 0.002 & 0.033 & 0.046 & 0.039 & -0.006 & -0.006 & 31.5 & 0.6 & 9.6 & 13.3 & 11.3 & -1.7 & -1.7 \\
\hline Washington-B & 0.621 & 0.571 & -0.050 & 0.000 & -0.276 & 0.082 & 0.059 & 0.082 & 0.002 & -8.0 & 0.1 & -44.4 & 13.3 & 9.5 & 13.2 & 0.4 \\
\hline Unweig. Average & 0.379 & 0.439 & 0.062 & 0.000 & -0.046 & 0.016 & 0.008 & 0.085 & 0.000 & 24.8 & -0.3 & -6.5 & 2.7 & 3.4 & 24.8 & 0.6 \\
\hline $\mathrm{CV}$ & 0.399 & 0.297 & & & & & & & & & & & & & & \\
\hline
\end{tabular}

Table 3: Unconditional and conditional segregation of Hispanic male workers in selected MAs $\left(\Phi_{1}^{H . M e n}\right)$ 


\begin{tabular}{|c|c|c|c|c|c|c|c|c|c|c|c|c|c|c|c|c|}
\hline \multirow[b]{2}{*}{ MAs } & \multicolumn{2}{|c|}{ Female Segregation } & \multicolumn{7}{|c|}{ Change in segregation } & \multicolumn{7}{|c|}{ Change as percentage of unconditional segregation } \\
\hline & Uncond. & Cond. & All & Age & Immig. & English & Education & Country & Race & All & Age & Immig. & English & Education & Country & Race \\
\hline Albuquerque & 0.243 & 0.390 & 0.146 & 0.001 & 0.077 & 0.007 & -0.014 & 0.074 & 0.002 & 60.1 & 0.3 & 31.5 & 2.8 & -5.7 & 30.5 & 0.6 \\
\hline Atlanta & 0.315 & 0.338 & 0.023 & 0.002 & -0.161 & 0.039 & 0.017 & 0.126 & 0.000 & 7.3 & 0.6 & -51.1 & 12.5 & 5.5 & 39.9 & 0.0 \\
\hline Austin-SM & 0.278 & 0.346 & 0.067 & 0.000 & 0.044 & 0.023 & -0.009 & 0.010 & 0.000 & 24.2 & -0.1 & 15.8 & 8.2 & -3.3 & 3.7 & 0.0 \\
\hline Boston-W-L & 0.276 & 0.311 & 0.035 & 0.004 & -0.039 & 0.006 & 0.024 & 0.035 & 0.005 & 12.6 & 1.4 & -14.2 & 2.4 & 8.5 & 12.7 & 1.8 \\
\hline Chicago-G-K & 0.230 & 0.225 & -0.004 & 0.001 & -0.018 & -0.023 & 0.019 & 0.019 & -0.002 & -1.9 & 0.6 & -7.9 & -10.0 & 8.2 & 8.4 & -1.1 \\
\hline Dallas-FW & 0.283 & 0.284 & 0.001 & 0.001 & -0.002 & 0.005 & -0.020 & 0.012 & 0.006 & 0.4 & 0.3 & -0.7 & 1.8 & -7.1 & 4.2 & 2.0 \\
\hline Denver-B-G & 0.279 & 0.332 & 0.053 & 0.003 & -0.002 & 0.042 & -0.030 & 0.045 & -0.004 & 19.2 & 0.9 & -0.8 & 14.9 & -10.7 & 16.1 & -1.3 \\
\hline El Paso & 0.214 & 0.216 & 0.002 & 0.000 & 0.005 & 0.000 & 0.007 & -0.009 & -0.002 & 0.7 & 0.1 & 2.5 & 0.0 & 3.1 & -4.1 & -0.9 \\
\hline Fresno & 0.203 & 0.203 & 0.000 & 0.001 & 0.000 & 0.003 & -0.002 & -0.001 & -0.001 & -0.2 & 0.3 & -0.2 & 1.4 & -0.7 & -0.5 & -0.5 \\
\hline Houston-G-B & 0.324 & 0.321 & -0.003 & 0.004 & 0.013 & -0.003 & -0.022 & 0.004 & 0.002 & -0.8 & 1.2 & 4.2 & -1.0 & -6.9 & 1.1 & 0.6 \\
\hline Las Vegas & 0.337 & 0.319 & -0.017 & -0.005 & -0.020 & 0.034 & -0.044 & 0.017 & 0.000 & -5.2 & -1.5 & -5.9 & 10.0 & -12.9 & 5.0 & 0.1 \\
\hline L. Angeles-R-OC & 0.232 & 0.232 & & & & & & & & & & & & & & \\
\hline McAllen-E-M & 0.225 & 0.252 & 0.028 & 0.001 & -0.007 & 0.021 & 0.001 & 0.017 & -0.005 & 12.5 & 0.5 & -3.3 & 9.2 & 0.3 & 7.7 & -2.1 \\
\hline Miami-FL & 0.174 & 0.283 & 0.109 & -0.001 & 0.011 & 0.012 & 0.010 & 0.062 & 0.014 & 62.2 & -0.3 & 6.4 & 6.8 & 5.7 & 35.6 & 8.1 \\
\hline New Y.- NNJ, LI & 0.238 & 0.285 & 0.047 & 0.001 & -0.061 & -0.033 & 0.046 & 0.097 & -0.002 & 20.0 & 0.3 & -25.6 & -13.8 & 19.5 & 40.7 & -1.0 \\
\hline Orlando & 0.213 & 0.358 & 0.146 & 0.000 & -0.047 & -0.007 & 0.029 & 0.175 & -0.004 & 68.5 & -0.2 & -22.3 & -3.2 & 13.4 & 82.5 & -1.7 \\
\hline Philadelphia-W-AC & 0.260 & 0.336 & 0.077 & -0.004 & -0.062 & -0.011 & -0.013 & 0.166 & 0.000 & 29.5 & -1.4 & -23.8 & -4.3 & -4.9 & 63.8 & 0.1 \\
\hline Phoenix-M & 0.247 & 0.251 & 0.004 & 0.002 & -0.006 & 0.017 & -0.012 & 0.004 & -0.001 & 1.8 & 0.9 & -2.3 & 6.9 & -4.7 & 1.4 & -0.4 \\
\hline Sacramento-Y & 0.228 & 0.298 & 0.070 & 0.001 & -0.002 & 0.039 & 0.023 & 0.009 & 0.000 & 30.8 & 0.3 & -0.7 & 17.0 & 10.2 & 4.0 & 0.0 \\
\hline San Antonio & 0.219 & 0.251 & 0.032 & 0.002 & 0.023 & 0.004 & -0.002 & -0.001 & 0.006 & 14.6 & 0.7 & 10.4 & 1.9 & -0.7 & -0.3 & 2.7 \\
\hline San Diego & 0.274 & 0.307 & 0.032 & 0.001 & -0.012 & 0.010 & 0.023 & 0.010 & 0.000 & 11.8 & 0.3 & -4.4 & 3.6 & 8.5 & 3.7 & 0.0 \\
\hline S. Francisco-0-SJ & 0.280 & 0.326 & 0.046 & -0.001 & -0.015 & 0.019 & 0.037 & 0.007 & 0.000 & 16.4 & -0.4 & -5.4 & 6.7 & 13.1 & 2.3 & -0.1 \\
\hline Tampa-SP-C & 0.182 & 0.319 & 0.136 & 0.000 & -0.044 & 0.013 & 0.003 & 0.152 & 0.012 & 74.7 & 0.1 & -23.9 & 7.0 & 1.5 & 83.3 & 6.6 \\
\hline Tucson & 0.262 & 0.301 & 0.039 & 0.002 & 0.012 & 0.013 & 0.002 & 0.012 & -0.002 & 15.0 & 0.7 & 4.5 & 5.1 & 0.6 & 4.7 & -0.7 \\
\hline Washington-B & 0.418 & 0.370 & -0.048 & 0.000 & -0.142 & 0.048 & 0.060 & -0.025 & 0.010 & -11.5 & 0.0 & -33.9 & 11.6 & 14.4 & -6.0 & 2.5 \\
\hline Unweig. Average & 0.257 & 0.298 & 0.043 & 0.001 & -0.019 & 0.012 & 0.006 & 0.042 & 0.001 & 0.043 & 0.001 & -0.019 & 0.012 & 0.006 & 0.042 & 0.001 \\
\hline CV & 0.206 & 0.166 & & & & & & & & & & & & & & \\
\hline
\end{tabular}

Table 4: Unconditional and conditional segregation of Hispanic female workers in selected MAs ( $\Phi_{1}^{\text {H.Women }}$ ) 
Tables 3 and 4 additionally identify the country of origin as the main factor explaining the discrepancy between segregation in Los Angeles and the remaining areas. This factor is responsible for the largest increase in segregation after conditioning on characteristics, followed by English fluency. As opposed to these factors, the immigration profile tends to reduce rather than increase segregation. In other words, the distribution of country of origin and, to a lesser extent, English proficiency in Los Angeles is generally more segregative than in the rest of the areas, while the opposite is true for the immigration profile. Other characteristics, such as race or age, seem to be less relevant, while education turns out to be relevant only in some areas.

When exploring the effect of conditioning on characteristics across MAs in more detail, we find that Dallas, Las Vegas and, to a lesser extent, Houston, all are no longer among the most segregated areas. Moreover, the segregation level is reduced in Las Vegas and Houston for both women and men (and also in Phoenix and Dallas, in the case of men). By contrast, several areas, including Orlando, Tampa, Miami, Boston, and New York experienced a remarkable increase in segregation for men (Table 3, column 3). This is a consequence of the differences between these areas and Los Angeles regarding the two factors mentioned above-origin and immigration profile. These areas would have higher segregation if they had the same distribution of Hispanics by origin as Los Angeles has. This would involve increasing the weight assigned to Mexicans in these areas and reducing that of other groups. ${ }^{16}$ This suggests that, among Hispanic men, those of Mexican origin tend to face higher segregation and, therefore, those MAs with lower presence of this group tend to exhibit less segregation. The effect of immigration is generally the opposite. If these areas had a profile similar to Los Angeles, which has a lower proportion of recent immigrants, their male segregation would be lower. Therefore, the unconditional segregation of males in these areas seems to be lower than the conditional segregation because of the lower presence of Mexicans, as compared to Los Angeles, though this effect is partially compensated for by the more recent immigration in these areas.

Among the areas that experienced important increases in female segregation after controlling for workers' characteristics, we find Albuquerque, Austin and again Orlando, Tampa, and Miami. This means that the first three of these areas join the list of

\footnotetext{
${ }^{16}$ This implies reducing Puerto Ricans in Tampa, Boston, New York, and Orlando; Cubans in Tampa and Miami; and Central and South Americans in Boston, Miami, and New York.
} 
the most segregated, while Miami is no longer the area with the lowest segregation. The effect of origin in all of these areas is the same as in the case of men: If these areas had the same composition as Los Angeles, female segregation there would be higher. It seems, therefore, that the low initial values of the three MAs located in Florida were in part a consequence of the MAs' large proportion of Hispanic groups facing lower segregation than Mexicans. In any case, as opposed to Orlando and Tampa, Miami still exhibits a relatively low conditional segregation level. ${ }^{17}$

It follows then that once the characteristics of Hispanics are taken into account, the highest segregation for women are found in Albuquerque, Washington D.C., Orlando, Austin, Atlanta, Philadelphia, Denver, and San Francisco (values ranging between 0.39 and 0.33); while the highest values for men are in Atlanta, Philadelphia, Tampa, Washington D.C., Denver, Sacramento, San Francisco, Orlando, and Boston (with values between 0.73 and 0.51). Consequently, Washington D.C., Atlanta, Philadelphia, Denver, and San Francisco maintain their initial positions, suggesting that the characteristics of their Hispanic populations do not explain the discrepancies of these MAs with respect to the remaining areas.

On the other hand, the lowest female segregation is found in Fresno, El Paso, Chicago, Los Angeles, San Antonio, Phoenix (which loses seven positions in the ranking), and McAllen (whose values range between 0.20 and 0.25 ). The lowest values for men are those of McAllen, El Paso, Fresno, Los Angeles, San Antonio, and Miami (ranging between 0.16 and 0.34 ). Once again, in the male case, these MAs coincide with those having the highest representation of Hispanics. The case of Albuquerque is remarkable, as it shows an intermediate level of segregation despite having a high representation of Hispanics.

Regarding the three largest MAs, we find that if we exclude New York, the other two areas notably improve the segregation of Hispanics when controlling for their characteristics. The case of Chicago is worth mentioning: It is among the MAs with the lowest female conditional segregation and loses seven positions in the male ranking as well. In addition, Los Angeles becomes one of the least segregated areas for both women and men.

\footnotetext{
${ }^{17}$ The role of immigration differs, however, between these MAs, being strongly positive in Albuquerque and negative in Orlando and Tampa. The reason for this is that, unlike these latter two areas, Albuquerque has a much higher proportion of Hispanics born in the U.S. than does Los Angeles.
} 
Once again, there is no evidence of a clear spatial pattern of segregation, although the lowest segregation appears in MAs located near the Mexican border. The analysis also reveals that the places with the highest conditional segregation are mainly new immigrant destinations, while those with the lowest conditional segregation are established immigrant gateways (which departs from what has been observed in the case of residential segregation (see Park and Iceland, 2011), where this classification is offered). ${ }^{18}$ Exceptions are the Boston and Tampa areas, which are established immigrant gateways where Hispanic men are highly segregated, and Phoenix, which is a new destination with low segregation for Hispanic women. It is important to note, however, that the different performance of new destinations as compared to established gateways does not seem the result of discrepancies in the characteristics of Hispanics between both types of places, as conditional segregation does control for those attributes. ${ }^{19}$ The cause of these disparities may be the different attitudes toward Hispanics, considering that in established gateways, Hispanics tend to be more evenly distributed across occupations.

\section{Controlling for the Characteristics of MAs}

In the previous section, we controlled for the characteristics of Hispanics in order to make segregation across metropolitan areas comparable. In this section, we go a step further and explore the characteristics of metropolitan areas that lead them to have more segregative labor markets for Hispanics. For this purpose, we undertake a regression analysis in which the explained variable is the conditional segregation of Hispanic women and men in each MA (i.e., the segregation of these groups measured using the same distribution of Hispanic worker attributes (those mentioned in the previous section) as in Los Angeles). In doing so, we keep the previous categorization of occupations (52 occupations) and extend the list of MAs. To prevent the small-unit bias problem that leads to overestimating the segregation level of groups with small samples, we only study those areas that have at least 520 Hispanic women (or men) in the

\footnotetext{
${ }^{18}$ The Spearman rank correlation between conditional segregation and percentage of Hispanics who have lived in the U.S. for less than 5 years is 0.68 for men and 0.38 for women, which suggests that the relationship is stronger in the male case.

${ }_{19}$ Our findings are consistent with those obtained by Lichter et al. (2010) regarding residential segregation, as they found that discrepancies between old and new destinations remain after controlling for several indicators.
} 
sample. This results in 101 observations (57 locations for men and 44 for women), which jointly account for $88.2 \%$ of Hispanic workers in the MAs (81.5\% of total Hispanic workers in the U.S.). Table 5 reports the OLS estimates for various specifications.

As mentioned above, occupational segregation of Hispanics is expected to depend on certain characteristics of metropolitan areas, such as their industrial structure or the characteristics of non-Hispanic populations. Indeed, those areas with higher shares of manufacturing or public administration are likely to be less segregative. The human capital level of a metropolitan area can also affect the job opportunities available to Hispanics because the job requirements demanded in a highly-educated labor market are expected to augment, while competition with other minorities probably grows stronger. Therefore, a higher educational level in the local market is likely to increase the occupational segregation of Hispanics. The number of Hispanics and the representation of other minorities may influence the competition effect as well, although the direction of this effect is not clear. The segregation of Hispanics will decrease as the representation of other minorities increases only if Hispanics are preferred to other minorities. On the other hand, as already mentioned, the larger the proportion of Hispanics in a local market, the more similar to that of the area is expected to be the distribution of employment of Hispanics. But occupational opportunities for Hispanics also depend on the particular conditions they face in local labor markets. For this reason, we also control for characteristics of the local labor market, such as unemployment rates faced by Hispanics, size of the metropolitan labor force (which is a variable commonly used to explain residential segregation), and the attitudes of non-Hispanics toward Hispanics, as these could bias their access to jobs. The latter variable is measured as the average feelings of non-Hispanics toward Hispanics on a scale from 1 (very warm) to 9 (very cool) across nine geographical regions, and it is taken from the 2002 General Social Survey. ${ }^{20}$

Accordingly, variables used in the regression analysis, all of them referring to the metropolitan level, are the following: A dummy variable that indicates whether the group is of women (WOMEN) to control for systematic differences in segregation

\footnotetext{
${ }^{20}$ The regions and the corresponding values are: New England (3.89), Middle Atlantic (3.72), East North Central (3.58), West North Central (3.56), South Atlantic (4.00), East South Central (4.33), West South Central (3.52), Mountain (3.45), and Pacific (3.21).
} 
among Hispanic women and men; number of workers, in millions (MA SIZE), and number of workers raised to two (MA SQUARED); percentage of Hispanic workers (\% $\mathrm{H}$ ); percentage of non-Hispanic workers speaking English “not well” or "not at all” (\% NH WITH LOW ENGLISH PROFICIENCY); percentage of non-Hispanic workers with a bachelor's degree or higher educational level (\% NH WITH BACHELOR'S DEGREE); percentage of workers who are (non-Hispanic) African Americans or Native Americans (\% AFRICAN A. + NATIVE A.); percentage of workers, based on the NAICS at 14 groups, in the manufacturing industry (\% MANUFACTURING), in the category labeled "professional, scientific, and management, and administrative and waste management services” (\% PROFESSIONALS), and in "public administration" (\% PUBLIC ADMINISTRATION); average feeling of non-Hispanics toward Hispanics (FEELINGS TOWARD H); and unemployment rate of Hispanic workers at least 16 years old (H UNEMPLOYMENT RATE).

\begin{tabular}{|c|c|c|c|c|c|c|c|c|c|}
\hline Explanatory variables & 1 & 2 & 3 & 4 & 5 & 6 & 7 & 8 & 9 \\
\hline WOMEN & $\begin{array}{l}-0.159 \star \star \star \\
(0.026)\end{array}$ & $\begin{array}{l}-0.161^{\star \star \star} \\
(0.026)\end{array}$ & $\begin{array}{l}-0.137^{\star \star \star} \\
(0.021)\end{array}$ & $\begin{array}{l}-0.134^{\star \star \star} \\
(0.020)\end{array}$ & $\begin{array}{l}-0.137^{\star \star \star \star} \\
(0.020)\end{array}$ & $\begin{array}{l}-0.136^{\star \star \star} \\
(0.019)\end{array}$ & $\begin{array}{l}-0.134^{\star \star \star} \\
(0.019)\end{array}$ & $\begin{array}{l}-0.132^{\star \star \star} \\
(0.019\end{array}$ & $\begin{array}{l}-0.128 \star \star \star \\
(0.018)\end{array}$ \\
\hline MA SIZE (mill.) & & $\begin{array}{l}0.026 \\
(0.017)\end{array}$ & $\begin{array}{l}-0.035^{\star *} \\
(0.016)\end{array}$ & $\begin{array}{l}-0.026 \\
(0.016)\end{array}$ & $\begin{array}{l}-0.047^{\star \star \star} \\
(0.016)\end{array}$ & $\begin{array}{l}-0.063^{\star \star \star} \\
(0.017)\end{array}$ & $\begin{array}{l}-0.052^{\star \star \star} \\
(0.018)\end{array}$ & $\begin{array}{l}-0.043^{\star \star} \\
(0.018)\end{array}$ & $\begin{array}{l}-0.047^{\star \star} \\
(0.018)\end{array}$ \\
\hline MA SQUARED & & $\begin{array}{l}-0.003^{\star} \\
(0.002)\end{array}$ & \begin{tabular}{|l}
0.002 \\
$(0.002)$
\end{tabular} & $\begin{array}{l}0.002 \\
(0.002)\end{array}$ & $\begin{array}{l}0.004^{\star *} \\
(0.002)\end{array}$ & $\begin{array}{l}0.005^{\star \star \star} \\
(0.002)\end{array}$ & $\begin{array}{l}0.004^{\star *} \\
(0.002)\end{array}$ & $\begin{array}{l}0.003 \\
(0.002)\end{array}$ & $\begin{array}{l}0.003^{\star} \\
(0.002)\end{array}$ \\
\hline$\% \mathrm{H}$ & & & $\begin{array}{l}-0.004^{\star \star \star} \\
(0.001)\end{array}$ & $\begin{array}{l}-0.004^{\star \star *} \\
(0.001)\end{array}$ & $\begin{array}{l}-0.005^{\star \star \star \star} \\
(0.001)\end{array}$ & $\begin{array}{l}-0.004^{\star \star \star} \\
(0.001)\end{array}$ & $\begin{array}{l}-0.005^{\star \star \star} \\
(0.001)\end{array}$ & $\begin{array}{l}-0.005^{\star \star \star} \\
(0.001)\end{array}$ & $\begin{array}{l}-0.005^{\star \star \star} \\
(0.001)\end{array}$ \\
\hline \% NH WITH LOW ENGLISH PROF. & & & & $\begin{array}{l}-0.030 * * \\
(0.014)\end{array}$ & $\begin{array}{l}-0.023^{\star} \\
(0.013)\end{array}$ & $\begin{array}{l}-0.021^{*} \\
(0.013)\end{array}$ & $\begin{array}{l}-0.022^{*} \\
(0.013)\end{array}$ & $\begin{array}{l}-0.018 \\
(0.013)\end{array}$ & $\begin{array}{l}-0.01 \\
(0.013)\end{array}$ \\
\hline \% NH WITH BACHELOR'S DEG. & & & & & $\begin{array}{l}0.005^{\star \star \star} \\
(0.002)\end{array}$ & $\begin{array}{l}0.005^{\star \star \star} \\
(0.001)\end{array}$ & $\begin{array}{l}0.008^{\star \star \star} \\
(0.002)\end{array}$ & $\begin{array}{l}0.007^{\star \star \star *} \\
(0.002)\end{array}$ & $\begin{array}{l}0.007^{\star \star \star} \\
(0.002)\end{array}$ \\
\hline \% AFRICAN A. + NATIVE A. & & & & & & $\begin{array}{l}0.005^{\star \star *} \\
(0.002)\end{array}$ & $\begin{array}{l}0.005^{\star \star *} \\
(0.002)\end{array}$ & $\begin{array}{l}0.001 \\
(0.003)\end{array}$ & $\begin{array}{l}0.001 \\
(0.003)\end{array}$ \\
\hline$\%$ MANUFACTURING & & & & & & & $\begin{array}{l}-0.007^{\star} \\
(0.004)\end{array}$ & $\begin{array}{l}-0.003 \\
(0.004)\end{array}$ & $\begin{array}{l}-0.001 \\
(0.004)\end{array}$ \\
\hline \% PROFESSIONALS & & & & & & & $\begin{array}{l}-0.012 \\
(0.007)\end{array}$ & $\begin{array}{l}-0.010 \\
(0.007)\end{array}$ & $\begin{array}{l}-0.016 \\
(0.008)\end{array}$ \\
\hline \% PUBLIC ADMINISTRATION & & & & & & & $\begin{array}{l}-0.005 \\
(0.006)\end{array}$ & $\begin{array}{l}0.000 \\
(0.006)\end{array}$ & $\begin{array}{l}0.003 \\
(0.006)\end{array}$ \\
\hline FEELINGS TOWARD H & & & & & & & & $\begin{array}{l}0.116^{\star *} \\
(0.050)\end{array}$ & $\begin{array}{l}0.113^{\star *} \\
(0.050)\end{array}$ \\
\hline H UNEMPLOYMENT RATE & & & & & & & & & $\begin{array}{l}-0.959^{*} \\
(0.497)\end{array}$ \\
\hline Intercept & $\begin{array}{l}0.476^{\star \star \star} \\
(0.017)\end{array}$ & $\begin{array}{l}0.458^{\star \star \star} \\
(0.022)\end{array}$ & $\begin{array}{l}0.623^{\star \star \star *} \\
(0.028)\end{array}$ & $\begin{array}{l}0.647^{\star \star \star \star} \\
(0.030)\end{array}$ & $\begin{array}{l}0.511^{\star \star *} \\
(0.051)\end{array}$ & $\begin{array}{l}0.448^{\star \star \star} \\
(0.053)\end{array}$ & $\begin{array}{l}0.585^{\star \star \star} \\
(0.090)\end{array}$ & $\begin{array}{l}0.155 \\
(0.207)\end{array}$ & $\begin{array}{l}0.251 \\
(0.210)\end{array}$ \\
\hline N. of observations & 101 & 101 & 101 & 101 & 101 & 101 & 101 & 101 & 101 \\
\hline $\mathbf{R}^{2}$ & 0.276 & 0.297 & 0.560 & 0.582 & 0.624 & 0.655 & 0.670 & 0.688 & 0.701 \\
\hline Adjusted $\mathrm{R}^{2}$ & 0.268 & 0.276 & 0.542 & 0.560 & 0.600 & 0.630 & 0.633 & 0.650 & 0.660 \\
\hline
\end{tabular}

Table 5. OLS regression results for segregation of Hispanics across U.S. MAs, 2005-07 ( $\Phi_{1}^{H}$ index). Note: H=Hispanics; $\mathrm{NH}=$ Non-Hispanics. Significance: $(*) 10 \%$; $\left({ }^{* *}\right) 5 \%$; $\left({ }^{* * *}\right) 1 \%$. Standard errors in parenthesis. 
The first column in Table 5 confirms our previous finding for selected MAs: On average, Hispanic women have lower segregation than men, with the coefficient remaining highly significant after controlling for the rest of variables (only reducing its magnitude by less than 20\%). The second specification shows that, before controlling for characteristics other than sex, the size of the metropolitan labor market (MA SIZE) does not appear to be relevant, only its squared value (MA SQUARED) has a significant negative effect. However, after controlling for other characteristics of local labor markets, it turns out that the distribution of employment of Hispanics across occupations becomes significantly less concentrated as the size of the labor market increases, but at a decreasing rate, with the lowest level of occupational segregation in areas of about 8 million workers. This finding is in line with that obtained by Ovadia (2003) for segregation between African Americans and whites.

The share of Hispanic workers in the area also has a negative and significant effect (Specification 3) that persists after controlling for other characteristics (Specifications 4-9), and that is consistent with the correlation analysis shown in the previous section. This result, which differs from that obtained by Semyonov et al. (2000) for segregation between African Americans and whites, might be driven by the fact that in some MAs, Hispanics account for a large proportion of the labor market. Including this variable in the regression allows us to control for this fact when measuring the effect of other characteristics of MAs on measuring local segregation.

The proportion of non-Hispanic workers with low English fluency has a negative and significant association with segregation of Hispanics in specifications 4 to 7 , which suggests that in areas with more low-skilled non-Hispanic immigrants, Hispanics are more evenly distributed across occupations. Yet, this effect completely vanishes after controlling for feelings toward Hispanics and Hispanic unemployment rates (Specifications 8 and 9), thus suggesting that the later covariates have a stronger degree of association with segregation. The effect of a high educational level of non-Hispanics in the area (\% NH WITH BACHELOR'S DEGREE) is highly significant and positive (i.e., as expected, a highly-educated labor force causes Hispanics to concentrate in fewer occupations). 
The analysis reveals that the proportion of other minorities in the area (\% AFRICAN A. + NATIVE A.) has a positive and significant effect on Specifications 6 and 7. It seems, therefore, that Hispanics tend to be more unevenly distributed across occupations when the representation of African Americans and Native Americans in the area is high. This result seems to be in line with Semyonov et al. (2000), as they found that segregation between African Americans and whites tends to decrease with the presence of Hispanic population. However, this effect vanishes again once we control for feelings toward Hispanics, which again suggests that it is the latter characteristic that is most strongly associated with segregation of Hispanics.

The industrial composition of MAs is first introduced in Specification 7. It seems to play no special role in explaining segregation of Hispanics. The coefficient corresponding to the percentage of workers in manufacturing (\% MANUFACTURING) has a significant and negative effect on this model, but its significance is lost after we control for additional variables. The fact that the public administration does not appear as a significant variable may be a consequence of its low weight and variability in the cities included in the sample (an exception is Washington, D.C.).

The coefficient of feelings toward Hispanics appears to be significant and have a strong positive effect. Thus, the cooler are the feelings towards workers of this ethnicity, the higher their occupational segregation tends to be. It is worth remembering that when including this variable in the model, the effects of other covariates vanish, such as the proportions of professionals and of non-Hispanics of other minorities or non-Hispanics with low-English proficiency. This suggests that the segregation of Hispanics tends to be greater in those areas with a high representation of African Americans and Native Americans and low recent immigration rates for other groups. But this effect seems to be associated with the fact that these areas turn out to be also those with a stronger negative attitude toward Hispanics. Note that even if this model does not imply a causal relationship between both variables, feelings toward Hispanics appears to have a stronger and more robust association with segregation of Hispanics.

Finally, other local labor market conditions faced by Hispanics, proxied by their unemployment rates, are strongly negative and significant. ${ }^{21}$ The fact that Hispanics

\footnotetext{
21 We have also used alternative unemployment rates. The unemployment rate for non-Hispanics turned out to have no effect, while the unemployment rate for all workers had a smaller effect. Thus, it seems to
} 
tend to be less segregated in those areas where they suffer higher unemployment rates seems to suggest that unemployment (before the economic recession) mostly affected those occupations in which Hispanics tend to concentrate the most. In other words, we can find that in some areas, the segregation of Hispanics could be relatively low only as the result of a weak local labor market not providing enough jobs for them.

\section{Final Comments}

This paper has given evidence of the occupational segregation of Hispanics in the largest Hispanic enclaves of the U.S. Toward that purpose, we used tools that allowed us to quantify the segregation of a target group without comparing it with each of the remaining demographic groups into which the economy can be partitioned. This provides a methodological advantage over most segregation analyses. We have also explored the role played by the characteristics of Hispanic workers in explaining the strong variation in the segregation of Hispanics across U.S. metropolitan areas. In doing so, we borrowed a propensity score procedure initially proposed in the literature to analyze wage disparities among demographic groups and adapted it to our context. In addition, using regression analysis, we explored the factors that make local labor markets more segregative places for Hispanics.

We found that the unconditional segregation of Hispanics across MAs is more heterogeneous and has a higher average for men than for women, which is in line with a previous work that used a broader classification of occupations (Alonso-Villar et al., 2012). Our analysis suggests that segregation is higher for men because they tend to work in occupations with a lower presence of other groups.

When controlling for differences in basic characteristics of Hispanics across MAs, we found that the country of origin and the immigration profile are the factors that primarily explain the spatial variability in segregation. Albuquerque, Orlando, and Austin in the case of women, and Tampa, Orlando, and Boston in the case of men, are among the areas with the highest conditional segregation. Therefore, the low segregation values that these areas have in the unconditional analysis seem to be a

be the unemployment rate of Hispanic workers that has the strongest association with their segregation. We have verified that the unemployment rate of Hispanics is not highly correlated with the presence of this group, $\% \mathrm{H}$, since the correlation coefficient between these variables is 0.21 . 
consequence of the attributes of the Hispanic population living there and not the result of a better integration of the group in these areas. The high (unconditional) segregation found in Washington D.C., Atlanta, Philadelphia, Denver, and San Francisco does not seem to be a consequence of the characteristics of their Hispanic populations, considering that conditional segregation in these areas is high as well. By contrast, segregation in MAs such as Dallas, Las Vegas, Phoenix, and, to a lesser extent, Houston, is reduced after imposing a common distribution of characteristics.

El Paso, Fresno, San Antonio, Los Angeles, and Chicago show the lowest conditional segregation for women and the first four of these areas, together with Miami and McAllen, have the lowest segregation for men. Therefore, less conditional segregation is detected in those MAs with the highest representation of Hispanics. Exceptions are Albuquerque, which has the highest conditional segregation for Hispanic women despite the high representation of Hispanics, and Chicago, which is among the lesser segregated MAs for women while Hispanics represent less than $20 \%$ of the workers in the area.

As a general picture of segregation, we found that the lowest conditional segregation appears in MAs located near the Mexican border. The analysis also revealed that the places with the highest conditional segregation are mainly new immigrant destinations, while those with the lowest segregation are established immigrant gateways (exceptions are Boston and Tampa, which are old destinations with high segregation for Hispanic men, and Phoenix, which is new destination with a low segregation for Hispanic women). This result differs from that obtained by Park and Iceland (2011) with respect to residential segregation, which suggested that residential and occupational segregation are two phenomena that do not necessarily move together.

The regression analysis of conditional segregation on the characteristics of MAs showed that segregation tends to be higher in relatively smaller MAs, with lower proportion of Hispanics, and with cooler attitudes towards people of this ethnicity. Further, a lower unemployment risk and a higher proportion of non-Hispanics with college degrees are also strongly associated with higher segregation. Other characteristics, such as the industrial structure and the presence of other minorities or non-Hispanic immigrants turn out to have a weaker degree of association with segregation of Hispanics. 


\section{References}

Albelda, R. (1986): “Occupational Segregation by Race and Gender, 1958-1981," Industrial and Labor Relations Review 39(3), 404-411.

Alonso-Villar, O. and Del Río, C. (2010): "Local versus Overall Segregation Measures,” Mathematical Social Sciences 60, 30-38.

Alonso-Villar, O., Del Río, C., and Gradín, C. (2012): “The Extent of Occupational Segregation in the US: Differences by Race, Ethnicity, and Gender," Industrial Relations, forthcoming.

Bayer, P., McMillan, R., and Rueben, K.S. (2004): "What Drives Racial Segregation? New Evidence Using Census Microdata,” Journal of Urban Economics 56, 514-535.

Black, D., Haviland, A., Sanders, S., and Taylor, L. (2006): "Why Do Minority Men Earn Less? A Study of Wage Differentials among the Highly Educated,” The Review of Economics and Statistics 88(1), 300-313.

Bradbury, K.L. (2002): "Education and Wages in the 1980s and 1990s: Are All Groups Moving Up Together?” New England Economic Review, First Quarter, 19-46.

Catanzarite, L. (2000): “Brown-Collar Jobs: Occupational Segregation and Earnings of Recent-Immigrant Hispanics,” Sociological Perspectives 43, 45-75.

Cohen, P.N., and Huffman, M.L. (2003): "Occupational Segregation and the Devaluation of Women's Work across U.S. Labor Markets,” Social Forces 81(3), 881908.

Chantreuil, F. and Trannoy, A. (1999): "Inequality Decomposition Values: The TradeOff between Marginality and Consistency,” THEMA Working Papers 99-24, Univesité de Cergy-Pontoise.

Census Bureau (2007): “Current Population Survey, 2007 Annual Social and Economic (ASEC) Supplement,” Census Bureau, Washington D.C., USA.

Cutler D.M., Glaeser, E.L. and Vigdor, J.L. (2008): "Is the Melting Pot still Hot? Explaining the Resurgence of Immigrant Segregation,” Review of Economics and Statistics. 90(3), 478-497.

Dávila, A. and Mora, M.T. (2008): "Changes in the Relative Earnings Gap between Natives and Immigrants along the U.S.-Mexico Border," Journal of Regional Science 48(3), 525-545.

DiNardo, J., Fortin, N., and Lemieux, T. (1996): "Labor Market Institutions and the Distribution of Wages, 1973-1992: A Semiparametric Approach,” Econometrica 64, 1001-1044.

Dickerson vonLockette, N.T. and Johnson, J. (2010): "Latino Employment and Residential Segregation in Metropolitan Labor Markets," Du Bois Review 7(1), 151184. 
Farley, R. (1977): "Residential Segregation in Urbanized Areas of the United States in 1970: An Analysis of Social Class and Racial Differences,” Demography 14(4), 497518.

Frey, W.H., and Farley, R. (1996): "Latino, Asian, and Black Segregation in U.S. Metropolitan Areas: Are Multiethnic Metros Different?” Demography 33(1), 35-50.

Frankel, D. M. and Volij, O. (2011): "Measuring School Segregation,” Journal of Economic Theory 146(1), 1-38.

Gabriel, P.E., Williams, D.R., and Schmitz, S. (1990): “The Relative Occupational Attainment of Young Blacks, Whites, and Hispanics,” Southern Economic Journal, 57(2), 35-46.

Gradín, C. (2010): “Conditional Occupational Segregation of Minorities in the US," ECINEQ WP2010-185, October.

Gradín, C., Del Río, C., and Alonso-Villar, O. (2011): “Occupational Segregation by Race and Ethnicity in the US: Differences across States,” ECINEQ WP2011-190, January.

Hao, L. and Fong, E. (2011): "Linking Dichotomous Segregation with Multi-Group Segregation: Weighted Segregation Ratios in Selected U.S. Metropolitan Areas,” Social Science Research 40, 379-391.

Hellerstein, J.K. and Neumark, D. (2008): "Workplace Segregation in the United States: Race, Ethnicity, and Skill,” Review of Economics and Statistics 90(3), 459-477.

Hirsch, B.T. and Macpherson, D.A. (2004): "Wages, Sorting on Skill, and the Racial Composition of Jobs,” Journal of Labor Economics 22(1), 189-210.

Iceland J. (2004): "Beyond Black and White. Metropolitan Residential Segregation in multi-ethnic America,” Social Science Research 33, 248-271.

Iceland, J. and Nelson, K.A. (2008): "Hispanic Segregation in Metropolitan America: Exploring the Multiple Forms of Spatial Assimilation,” American Sociological Review 73, 741-765.

Kaufman, R.L. (2002): “Assessing Alternative Perspectives on Race and Sex Employment Segregation,” American Sociological Review 67, 547-572.

Kaufman, R.L. (2010): Race, Gender, and the Labor Market: Inequalities at Work. Lynne Rienner Publishers, Boulder (CO), USA.

Kim, M. (2002): "Has the Race Penalty for Black Women Disappeared in the United States?” Feminist Economics 8(2), 115-124.

King, M. 1992: “Occupational Segregation by Race and Sex, 1940-88,” Monthly Labor Review 115, 30-37. 
Lichter, D.T., Parisi, D., Taquino, M.C., and Grice, S.M. (2010): "Residential segregation in new Hispanic destinations: Cities, suburbs, and rural communities compared,” Social Science Research 39, 215-230.

Logan, J.R., Stults, B.J., and Farley, R. (2004): "Segregation of Minorities in the Metropolis: Two decades of Change,” Demography, 41(1), 1-22.

Massey, D. and Denton, N. (1987): "Trends in the Residential Segregation of Blacks, Hispanics, and Asians: 1970-1980,” American Sociological Review 52(6), 802-825.

Maxwell, N. (2010): "English Language and Low-Skilled Jobs: The Structure of Employment,” Industrial Relations 49(3), 457-465.

Neal, D.A. and Johnson, W.R. (1996): "The Role of Premarket Factors in Black-White Wage Differences,” Journal of Political Economy 104(5), 869-895.

Ovadia, S. (2003): “The Dimensions of Racial Inequality: Occupational and Residential Segregation Across Metropolitan Areas in the United States," City \& Community 2(4), 313-333.

Park, J. and Iceland, J. (2011): "Residential Segregation in Metropolitan Established Immigrant Gateways and New Destinations, 1990-2000,” Social Science Research 40, 811-821.

Queneau, H. (2009): “Trends in Occupational Segregation by Race and Ethnicity in the USA: Evidence from Detailed Data,” Applied Economics Letters 16, 1347-1350.

Reardon, S.F., Farrell, C.R., Matthews, S.A., O’Sullivan, D., Bischoff, K., and Firebaugh, G. (2009): "Race and Space in the 1990s: Changes in the Geographic Scale of Racial Residential Segregation, 1990-2000,” Social Science Research 38, 55-70.

Reardon, S. and Yun, J. (2001): "Suburban Racial Change and Suburban School Segregation, 1987-95,” Sociology of Education 74, 79-101.

Reskin, B. (1999): “Occupational Segregation by Race and Ethnicity Among Women Workers.” In Irene Browne, ed., Latinas and African American Women at Work. Race, Gender, and Economic Inequality, 183-204. New York: Russell Sage Foundation.

Sastre, M. and Trannoy, A. (2002): "Shapley Inequality Decomposition by Factor Components: Some Methodological Issues,” Journal of Economics 9, 51-89.

Semyonov, M., Haberfeld, Y., Cohen, Y., and Lewin-Epstein, N. (2000): "Racial Composition and Occupational Segregation and Inequality across American Cities," Social Science Research 29, 175-187.

Stewart, Q.T. and Dixon, J.C. (2010): "Is it Race, Immigrant Status, or Both? An Analysis of Wage Disparities among Men in the United States," International Migration Review 44(1), 173-201.

Shorrocks, A. (1999): "Decomposition Procedures for Distributional Analysis: A Unified Framework Based on the Shapley Value,” Mimeo, University of Essex. 
Theil, H. and Finizza, A.J. (1971): "A Note on the Measurement of Racial Integration of Schools By Means of Informational Concepts,” Journal of Mathematical Sociology 1, 187-194.

Tomaskovic-Devey, D., Zimmer, C., Stainback, K., Robinson, C., Taylor, T. and McTague, T. (2006): "Documenting Desegregation: Segregation in American Workplaces by Race, Ethnicity, and Sex, 1966-2003," American Sociological Review 71, 565-588.

Wang, Q. (2008): "Race/Ethnicity, Gender and Job Earnings across Metropolitan Areas in the United States: A Multilevel Analysis,” Urban Studies 45(4), 825-843. 


\section{Appendix}

\begin{tabular}{|c|c|c|c|c|c|c|c|c|}
\hline MAs & $\begin{array}{l}\text { Population } \\
\text { [2000 U.S. } \\
\text { Census] }\end{array}$ & $\begin{array}{c}\text { African A. + } \\
\text { Native A. } \\
\text { (\%) }\end{array}$ & $\begin{array}{c}\text { Asians } \\
(\%)\end{array}$ & $\begin{array}{l}\text { Manufacturing } \\
(\%)\end{array}$ & $\begin{array}{c}\text { Public } \\
\text { Administ. } \\
(\%)\end{array}$ & $\begin{array}{c}\text { Hispanic } \\
\text { Unemployment }\end{array}$ & $\begin{array}{l}\text { Feelings } \\
\text { toward } \\
\text { Hispanics }\end{array}$ & $\begin{array}{l}\text { Hispanics of } \\
\text { Mexican } \\
\text { origin (\%) } \\
\end{array}$ \\
\hline Albuquerque, NM & 712,738 & 7.0 & 1.9 & 7.3 & 6.0 & 0.075 & 3.5 & 41.1 \\
\hline Atlanta, GA & $4,112,198$ & 28.2 & 4.0 & 9.1 & 4.3 & 0.053 & 4.0 & 61.8 \\
\hline Austin-San Marcos, TX & $1,249,763$ & 6.9 & 4.0 & 9.8 & 6.5 & 0.068 & 3.5 & 79.1 \\
\hline $\begin{array}{l}\text { Boston-Worcester-Lawrence, } \\
\text { MA-NH-ME-CT }\end{array}$ & $5,819,100$ & 4.8 & 4.8 & 11.0 & 3.8 & 0.101 & 3.9 & 8.5 \\
\hline $\begin{array}{l}\text { Chicago-Gary-Kenosha, IL-IN- } \\
\text { WI }\end{array}$ & $9,157,540$ & 13.8 & 5.3 & 13.4 & 3.3 & 0.084 & 3.6 & 78.3 \\
\hline Dallas-Fort Worth, TX & $5,221,801$ & 12.6 & 4.4 & 11.6 & 3.1 & 0.068 & 3.5 & 83.6 \\
\hline Denver-Boulder-Greeley, CO & $2,581,506$ & 4.4 & 3.1 & 7.8 & 4.0 & 0.072 & 3.5 & 75.6 \\
\hline El Paso, TX & 679,622 & 3.2 & 0.8 & 9.2 & 6.4 & 0.095 & 3.5 & 93.0 \\
\hline Fresno, CA & 922,516 & 4.7 & 7.1 & 8.0 & 6.2 & 0.117 & 3.2 & 93.4 \\
\hline Houston-Galveston-Brazoria, TX & $4,669,571$ & 15.3 & 5.7 & 10.8 & 2.7 & 0.073 & 3.5 & 74.5 \\
\hline Las Vegas, NV-AZ & $1,563,282$ & 8.6 & 6.8 & 3.8 & 3.7 & 0.055 & 3.5 & 75.5 \\
\hline $\begin{array}{l}\text { Los Angeles-Riverside-Orange } \\
\text { County, CA }\end{array}$ & $16,400,000$ & 6.7 & 11.9 & 12.1 & 3.4 & 0.072 & 3.2 & 78.8 \\
\hline McAllen-Edinburg-Mission, TX & 569,463 & 0.7 & 1.0 & 4.5 & 3.9 & 0.108 & 3.5 & 93.7 \\
\hline Miami-Fort Lauderdale, FL & $3,876,380$ & 18.4 & 2.3 & 5.5 & 4.3 & 0.055 & 4.0 & 4.1 \\
\hline $\begin{array}{l}\text { New York, Northern New } \\
\text { Jersey, Long Island, NY-NJ-CT- } \\
\text { PA }\end{array}$ & $21,200,000$ & 14.5 & 8.5 & 7.6 & 4.2 & 0.083 & 3.9 & 12.5 \\
\hline Orlando, FL & $1,644,561$ & 13.5 & 3.4 & 5.1 & 3.2 & 0.073 & 4.0 & 15.9 \\
\hline $\begin{array}{l}\text { Philadelphia-Wilmington-Atlantic } \\
\text { City, PA-NJ-DE-MD }\end{array}$ & $6,188,463$ & 15.9 & 4.2 & 10.1 & 4.5 & 0.091 & 3.7 & 27.3 \\
\hline Phoenix-Mesa, AZ & $3,251,876$ & 5.2 & 2.8 & 8.7 & 4.5 & 0.057 & 3.5 & 87.3 \\
\hline Sacramento-Yolo, CA & $1,796,857$ & 7.1 & 10.5 & 5.7 & 9.1 & 0.084 & 3.2 & 78.4 \\
\hline San Antonio, TX & $1,592,383$ & 6.1 & 2.0 & 6.7 & 5.3 & 0.073 & 3.5 & 81.9 \\
\hline San Diego, CA & $2,813,833$ & 5.5 & 10.3 & 8.5 & 5.6 & 0.069 & 3.2 & 86.3 \\
\hline $\begin{array}{l}\text { San Francisco-Oakland-San } \\
\text { Jose, CA }\end{array}$ & $7,039,362$ & 6.4 & 20.8 & 11.6 & 3.6 & 0.073 & 3.2 & 74.5 \\
\hline $\begin{array}{l}\text { Tampa-St. Petersburg- } \\
\text { Clearwater, FL }\end{array}$ & $2,395,997$ & 10.4 & 2.7 & 6.8 & 3.9 & 0.068 & 4.0 & 25.2 \\
\hline Tucson, AZ & 843,746 & 4.9 & 2.6 & 7.9 & 5.8 & 0.083 & 3.5 & 89.0 \\
\hline $\begin{array}{l}\text { Washington-Baltimore, DC-MD- } \\
\text { VA-WV }\end{array}$ & $7,608,070$ & 23.3 & 6.6 & 4.5 & 11.7 & 0.056 & 4.0 & 16.7 \\
\hline
\end{tabular}

Table 6. Additional characteristics of selected metropolitan areas 


\begin{tabular}{|c|c|c|c|c|c|c|}
\hline MAs & $\begin{array}{c}\text { Unconditional } \\
\text { Ranking } \\
\Phi_{1}^{H . M e n}\end{array}$ & $\begin{array}{c}\text { Conditional } \\
\text { Ranking } \\
\Phi_{1}^{H . M e n}\end{array}$ & $\begin{array}{c}\text { Ranking } \\
\text { Differences } \\
\text { H. Men }\end{array}$ & $\begin{array}{c}\text { Unconditional } \\
\text { Ranking } \\
\Phi_{1}^{H . \text { Women }}\end{array}$ & $\begin{array}{l}\text { Conditional } \\
\text { Ranking } \\
\Phi_{1}^{\text {H.Women }}\end{array}$ & $\begin{array}{c}\text { Ranking } \\
\text { Differences } \\
\text { H. Women }\end{array}$ \\
\hline Albuquerque, NM & 21 & 13 & -8 & 14 & 1 & -13 \\
\hline Atlanta, GA & 1 & 1 & 0 & 4 & 5 & 1 \\
\hline Austin-San Marcos, TX & 11 & 10 & -1 & 8 & 4 & -4 \\
\hline $\begin{array}{l}\text { Boston-Worcester-Lawrence, MA-NH- } \\
\text { ME-CT }\end{array}$ & 13 & 9 & -4 & 9 & 12 & 3 \\
\hline Chicago-Gary-Kenosha, IL-IN-WI & 10 & 17 & 7 & 17 & 23 & 6 \\
\hline Dallas-Fort Worth, TX & 5 & 15 & 10 & 5 & 17 & 12 \\
\hline Denver-Boulder-Greeley, CO & 4 & 5 & 1 & 7 & 7 & 0 \\
\hline El Paso, TX & 25 & 24 & -1 & 21 & 24 & 3 \\
\hline Fresno, CA & 20 & 23 & 3 & 23 & 25 & 2 \\
\hline Houston-Galveston-Brazoria, TX & 12 & 16 & 4 & 3 & 9 & 6 \\
\hline Las Vegas, NV-AZ & 9 & 19 & 10 & 2 & 10 & 8 \\
\hline $\begin{array}{l}\text { Los Angeles-Riverside-Orange County, } \\
\text { CA }\end{array}$ & 19 & 22 & 3 & 16 & 22 & 6 \\
\hline McAllen-Edinburg-Mission, TX & 24 & 25 & 1 & 19 & 19 & 0 \\
\hline Miami-Fort Lauderdale, FL & 23 & 20 & -3 & 25 & 18 & -7 \\
\hline $\begin{array}{l}\text { New York, Northern New Jersey, Long } \\
\text { Island, NY-NJ-CT-PA }\end{array}$ & 14 & 11 & -3 & 15 & 16 & 1 \\
\hline Orlando, FL & 17 & 8 & -9 & 22 & 3 & -19 \\
\hline $\begin{array}{l}\text { Philadelphia-Wilmington-Atlantic City, } \\
\text { PA-NJ-DE-MD }\end{array}$ & 3 & 2 & -1 & 12 & 6 & -6 \\
\hline Phoenix-Mesa, AZ & 7 & 14 & 7 & 13 & 20 & 7 \\
\hline Sacramento-Yolo, CA & 8 & 6 & -2 & 18 & 15 & -3 \\
\hline San Antonio, TX & 22 & 21 & -1 & 20 & 21 & 1 \\
\hline San Diego, CA & 18 & 18 & 0 & 10 & 13 & 3 \\
\hline San Francisco-Oakland-San Jose, CA & 6 & 7 & 1 & 6 & 8 & 2 \\
\hline Tampa-St. Petersburg-Clearwater, FL & 16 & 3 & -13 & 24 & 11 & -13 \\
\hline Tucson, AZ & 15 & 12 & -3 & 11 & 14 & 3 \\
\hline Washington-Baltimore, DC-MD-VA-WV & 2 & 4 & 2 & 1 & 2 & 1 \\
\hline
\end{tabular}

Table 7. Rankings by conditional and unconditional segregation of Hispanic men and women in selected MAs ( $\Phi_{1}^{H}$ index). 


\begin{tabular}{|l|c|c|c|c|}
\hline & \multicolumn{2}{|c|}{ Men } & \multicolumn{2}{c|}{ Women } \\
\hline & Coefficient & Stand. Error & Coefficient & Stand. Error \\
\hline Aged 30-45 & 0.010 & 0.041 & 0.102 & 0.048 \\
\hline Aged >45 & 0.041 & 0.057 & 0.154 & 0.066 \\
\hline Immigrant (<5 years) & -1.642 & 0.068 & -1.264 & 0.097 \\
\hline Immigrant (6-10 years) & -1.451 & 0.058 & -1.278 & 0.072 \\
\hline Immigrant (11-15 years) & -1.380 & 0.057 & -1.137 & 0.063 \\
\hline Immigrant (>15 years) & -0.492 & 0.043 & -0.386 & 0.046 \\
\hline English very well & -0.352 & 0.050 & -0.406 & 0.053 \\
\hline English well & -0.447 & 0.060 & -0.535 & 0.066 \\
\hline English not well & -0.544 & 0.063 & -0.719 & 0.070 \\
\hline English not at all & 0.010 & 0.077 & -0.491 & 0.085 \\
\hline High school diploma & -0.344 & 0.036 & -0.341 & 0.045 \\
\hline Some College or associate degree & -0.116 & 0.041 & -0.292 & 0.048 \\
\hline Bachelor's degree or higher & -0.376 & 0.051 & -0.683 & 0.057 \\
\hline Puerto Rico & -5.409 & 0.066 & -5.939 & 0.070 \\
\hline Cuban & -3.373 & 0.092 & -3.743 & 0.097 \\
\hline From rest of Central America & -2.395 & 0.034 & -2.974 & 0.042 \\
\hline South American/other Hispanic & -3.244 & 0.036 & -3.544 & 0.044 \\
\hline Non White & -0.139 & 0.028 & -0.128 & 0.033 \\
\hline Intercept & 3.512 & 0.063 & 3.899 & 0.076 \\
\hline & & & & \\
\hline Number of Observations & 65,077 & & 51,028 & \\
\hline Pseudo-R2 & 0.3841 & & 0.4549 & \\
\hline Wald Chi2(18) & 14,101 & & 11,272 & \\
\hline
\end{tabular}

Table 8. Logit regressions of the probability of being from Los Angeles (pooled sample of Hispanic workers in Los Angeles and New York)

Omitted: aged 16-29, born in the US, Speaks only English, less than High school, Mexican, and white. Similar regressions were run for the other MAs. 